\title{
18. TAKUYO-DAISAN GUYOT: DEPOSITIONAL HISTORY OF THE CARBONATE PLATFORM FROM DOWNHOLE LOGS AT SITE 879 (OUTER RIM) ${ }^{1}$
}

\author{
James G. Ogg, ${ }^{2}$ Gilbert F. Camoin, ${ }^{3}$ and Lubomir Jansa ${ }^{4}$
}

\begin{abstract}
The upper Aptian to Albian carbonate platform series at Site 879 consists of three main episodes of transgressive deepening followed by a general upward-shallowing succession. These depositional sequences typically have a transgressive to early-highstand depositional systems tract of quiet-water lagoon facies and a late-highstand to lowstand systems tract of shallow-lagoon to intertidal facies. The shallow-lagoon to intertidal facies display an internal cyclicity of $\sim 3$-m-thick upward-shoaling successions. If these short-term upward-shallowing cycles are related to Milankovitch climatic-oceanographic cooling cycles of the 100-k.y. period of eccentricity modulation of precession, then the 3-m-average thickness of these upward-shallowing cycles would then imply a 5-m.y. duration for the 164-m-thick carbonate platform. The basal biostratigraphic age, relative thicknesses, and a constant subsidence rate of $30 \mathrm{~m} / \mathrm{m} . \mathrm{y}$. for these carbonate platform successions are consistent with assignments to late Aptian Sequence LZB-4.1 through early Albian Sequence LZA-1.2. However, benthic foraminifer assemblages from the upper $40 \mathrm{~m}$ of the platform suggest a longer age span of accumulation.

The lowest depositional sequence (126-164 meters below seafloor [mbsf], 39 m thick) onlaps a 23-m-thick clay-rich, weathering zone on volcanic breccia and contains a total of 12 cycles. The cycle set is developed in mixed transgressive-carbonate and prograding-clastic facies in the lower $12 \mathrm{~m}$ and algal-cyanobacterial-rich shallow-lagoon to emergent facies in the upper $27 \mathrm{~m}$.

The second depositional sequence (88-126 mbsf, $38 \mathrm{~m}$ thick) is a $24-\mathrm{m}$-thick, deep-lagoon, foraminifer-pellet packstone followed by a 12 -m-thick interval with four main cycles of shallow-lagoon to intertidal facies.

The third depositional sequence (4-88 mbsf, $84 \mathrm{~m}$ thick) begins with $49 \mathrm{~m}$ of quiet lagoon facies, including $22 \mathrm{~m}$ of an unrecovered, low-porosity interval interpreted as uncemented pelletal lime mud. The upper portion of this third depositional sequence begins with a thin, oncolite-rich interval. This shallow-lagoon facies is followed by a series of four main episodes of winnowed gastropod-rich facies interbedded with redeposited coral-rich floatstone. These reworked deposits may represent the Cretaceous equivalent of storm-debris accumulations that construct the island rings of modern atolls, and such deposits may have also played a major role in constructing the rim-lagoon geomorphology of Takuyo-Daisan Guyot. However, the origin of the 70-m-high southern rim cannot be deduced from the limited logging data and core recovery, although the drilling results did not provide any evidence for either a wave-resistant bioherm construction or a solution edge-effect during prolonged subaerial exposure. The highest sediments in Hole 879A are a winnowed gastropod-rich peloid grainstone-coquina, which may be bioclastic sand shoals deposited during the initial transgressive stages of the final submergence of the guyot. The drowning of Takuyo-Daisan Guyot may have resulted from the combined effects of an accelerated transgressive rise of sea level during the early Albian and unfavorable environments in proximity to the paleoequator.
\end{abstract}

\section{OVERVIEW}

Takuyo-Daisan Guyot $\left(34.2^{\circ} \mathrm{N}, 144.3^{\circ} \mathrm{E}\right)$ is the easternmost guyot of the Seiko cluster in the Japanese Seamount province (see site map preceding title page). Site 879 is on the southern perimeter rim of the guyot platform, which rises approximately $70-80 \mathrm{~m}$ above the interior platform surface. Approximately $2.2 \mathrm{~km}$ north of Site 879 is a broad feature rising approximately $100 \mathrm{~m}$ above the platform surface, which may represent an emergent portion of the volcanic edifice.

The general stratigraphy is summarized by the Shipboard Scientific Party (1993). The upper volcanic edifice contains a series of lava flows and volcaniclastic sediments. A period of intensive subaerial weathering of the volcano slopes formed a clayey soil, which is over 20-mthick in Hole 879A. A progressive late Aptian flooding of this surface resulted in a 10-m succession of mixed skeletal and volcanic detritus, clay-rich limestone, and fine-grained limestone in a variable nearshore/lagoonal environment. This was followed by approximately

\footnotetext{
${ }^{1}$ Haggerty, J.A., Premoli Silva, L., Rack, F., and McNutt, M.K. (Eds.), 1995. Proc. ODP, Sci. Results, 144: College Station, TX (Ocean Drilling Program).

Department of Earth and Atmospheric Sciences, Purdue Univeristy, West Lafayette, IN 47907 , U.S.A

${ }^{3}$ Centre de Sédimentologie, CNRS, Université de Provence, 3 Place V. Hugo, F-13331, Marseilles Cedex 3, France.

${ }^{4}$ Atlantic Geoscience Centre, Bedford Institute of Oceanography, Dartmouth, Nova Scotia, B2Y 4A2, Canada.
}

$115 \mathrm{~m}$ of lagoonal to shoal facies of skeletal packstone, wackestone, and grainstone. The upper $40 \mathrm{~m}$ consists of coral-mollusk rudstone, indicating that a higher wave-energy environment preceded the Albian drowning of this perimeter rim of Takuyo-Daisan Guyot. Phosphatized chalk deposits encrust the drowned surface. Neogene nannofossil ooze, rich in volcanic ash, accumulated in depressions in the guyot center as the guyot approached the active Japanese arc.

Integration of logging data and cored lithologies enable a detailed analysis of this general facies development (Fig. 1, back pocket). Logs of different physical parameters, such as resistivity, density, and natural-gamma-ray intensity, supplemented by Formation MicroScanner (FMS) imagery indicate a complex stratigraphy of varying grain sizes and cementation. These physical properties and lithologic data have been merged into a meter-by-meter physical lithology column with associated interpretations of depositional environments and identification of possible sea-level trends. Three main depositional cycles of transgressive deepening through progradational shallowing could be identified in the carbonate platform succession.

The rimmed-lagoon geomorphology of Takuyo-Daisan Guyot was interpreted by Van Waasbergen and Winterer (1993) to be an artifact of a prolonged episode of subaerial exposure and large-scale karstsolution of the interior of the carbonate platform before final drowning, rather than exclusively a constructional feature. The drilling results from Site 879 did not directly support either a karst-solution origin or a bioherm construction for the south rim (Shipboard Scientific Party, 1993). This feature and possible events contributing to the 
final drowning of this guyot are discussed further in the concluding section to this paper.

\section{INTRODUCTION AND PROCEDURE FOR FACIES ANALYSIS}

One suite of geophysical tools and two passes of the FMS were run from the bottom of the suspended drill pipe at 40 meters below seafloor (mbsf) to the upper portion of the volcanic basalt flow facies at 214 mbsf. Because of different logging conditions for each tool string and the placement of different tools on the strings, the total depth penetration by each tool varies within these logging intervals.

Core recovery within the $164 \mathrm{~m}$ of platform carbonates in Hole $879 \mathrm{~A}$ averaged only about $4 \%$. Therefore, these logs are invaluable for interpreting the facies succession and sea-level fluctuations within the carbonate platform. In particular, the high-resolution microresistivity borehole-wall imagery from the FMS tool is excellent for determining the thickness and vertical succession of lithologies displaying similar "resistivity textures," which, in turn, can be assigned as specific carbonate facies.

The procedure for interpreting the depositional history of Site 879 from the combination of core recovery and downhole logs consists of the following steps.

1. Depths of logging runs are calibrated to each other and related to coring depths. The FMS logs are graphically displayed in various formats and scales for visual interpretation of resistivity features.

2. Distinct carbonate facies recovered in cores are compared to the logging data to obtain a characteristic logging "signature" to recognize these facies in intervals where core recovery was sparse. This "ground-truth" calibration was especially important for the FMS resistivity imagery.

3. A composite description of logging features and associated core recovery is made of the hole, which incorporates preliminary interpretation of the vertical succession of facies. The array of highresolution logging data enabled suites of lithologic subunits to be defined and parasequence trends to be distinguished.

4. The facies succession is interpreted in terms of shifting depositional environments and relative fluctuations in sea level. Possible correlation to sea-level fluctuations interpreted from French AptianAlbian outcrops is constrained by biostratigraphic control.

At each level of this chain of interpretations, various assumptions and models need to be incorporated; and we will make an effort to clarify most of these steps.

\section{CALIBRATION AND PROCESSING OF KEY LOGS}

\section{Depth Shifting}

Logging data are initially collected relative to the meters of logging wireline suspended below the drill rig floor and adjusted for the spacing of tools on the particular tool string. However, this initial array of data generally does not correspond to the cored intervals within the hole as measured by the lowered pipe during drilling operations. There are several factors that contribute to this mismatch, and a series of calibrations must be made, first to the position of the drill pipe, then between the different logs. Because of the very poor recovery throughout Hole $879 \mathrm{~A}$ and the inability to uniquely assign any of the few pieces of lithology to the detailed borehole logging, we used the compensated logging depths of the first pass of the FMS tools as the standard for all core descriptions and depths of features, rather than the "educated guesses" made by the shipboard party. The following two paragraphs summarize how these depths were derived.

The drill pipe during the logging runs is at a known depth below the dual-elevator stool on the rig floor (in turn, $11.7 \mathrm{~m}$ above mean sea level during the Site 879 drilling), and all cores were drilled with respect to this same reference. The initial contact of the drill string with the seafloor ("bottom felt depth") is then used to convert drilling depths to "meters below seafloor" (mbsf). This "bottom felt depth" was 1512.5 "meters below rig floor" (mbrf) for Hole 879A, implying that the seafloor was 1500.8 "meters below sea level" (mbsl). Therefore, the drill depths of cores (mbrf) were converted into depth within Hole 879A (mbsf) by subtracting $1512.5 \mathrm{~m}$ (Shipboard Scientific Party, 1993).

The different logging runs have varying degrees of stretch of the wireline. Therefore, a natural-gamma tool (NGT) is a part of each logging tool string, and distinctive natural-gamma peaks within the rock succession are used to depth-shift each log with respect to a standard run. The different logging records were later interactively depth shifted by the Lamont-Doherty Earth Observatory Borehole Research Group (LDEO-BRG) with reference to the NGT record from the first FMS run and to the depth of the seafloor.

Calibration of the logging depth scale (meters of wireline below the rig floor) to the drill core record was accomplished by LDEOBRG by identifying the base of the suspended drill pipe (meters below rig floor) in the response of the resistivity logs. During all logging runs in Hole $879 \mathrm{~A}$, the drill pipe was suspended at $1553.0 \mathrm{mbrf}$, or $40.5 \mathrm{~m}$ below the $1512.5 \mathrm{~m}$ "bottom felt depth" used to assign core depths, implying that it was $40.5 \mathrm{~m}$ into Hole 879A. However, the response of the resistivity logs, once shifted by LDEO-BGR to the "reference" FMS log, shows the bottom of the drill pipe at $\sim 1552.5 \mathrm{mbrf}$, which was $0.5 \mathrm{~m}$ higher than its actual depth. Therefore, LDEO-BRG applied a depth correction of $1512.0 \mathrm{~m}$, instead of $1512.5 \mathrm{~m}$, to convert meters below rig floor (mbrf) of the wireline logging depths of all logs to meters below seafloor (mbsf) within the drill hole. This correction factor would lower the wireline depths within the borehole by $0.5 \mathrm{~m}$. The other logs have been shifted upward or downward with respect to the NGT on the first FMS pass (the reference $\log$ ) to match distinct natural-gamma-ray peaks; similar corrections were performed independently by the Shipboard Scientific Party (i.e., see introduction to "Downhole Measurements and Seismic Stratigraphy" report in Shipboard Scientific Party, 1993).

In this summary of logging stratigraphy, all features are described relative to LDEO-BRG-processed "corrected" FMS depths, which are the scales for the FMS imagery on the well-log data compact disk (CD-ROM) distributed with the Ocean Drilling Program Initial Reports (Premoli Silva, Haggerty, Rack, et al., 1993). Pass \#1 of the FMS tool, as processed by LDEO-BRG, was selected as the primary depth reference scale.

However, the $0.5-\mathrm{m}$ correction by LDEO-BRG is less than the 1.0 - $\mathrm{m}$ downward depth shift to the same logs (i.e., addition of $1.0 \mathrm{~m}$ to recorded logging depths) made by the Shipboard Scientific Party. Therefore, some contacts are now assigned $0.5 \mathrm{~m}$ higher than were reported in the Site 879 initial report (Shipboard Scientific Party, 1993). The shipboard correction factor was probably a better estimate because the FMS Pass \#1, as depth shifted by LDEO-BRG, records resistivity features with apparent depths as high as $40.0 \mathrm{mbsf}$, which is $0.5 \mathrm{~m}$ higher than the presumed depth of the suspended drill pipe, that therefore should have been obscured.

There are additional complications, such as deducing the exact base of the drill pipe in the logging runs or identifying unique sharp features on the natural-gamma traces for precise depth shifting. In addition, the LDEO-BRG internally adjusts the two FMS runs with respect to each other in order to match common features to within a few centimeters. This internal depth-shifting of FMS traces is thought to be necessary because of differential stretching of the wireline during ocean swells or variable friction within the borehole. However, it was noted that distinctive resistivity features in the depth-processed Pass \#2 of the FMS tool were offset approximately 20 - to $30-\mathrm{cm}$ upward with respect to the same feature in reference Pass \#1.

The LDEO-BRG depth adjustments to the FMS runs are at a minor variance with respect to the depth-corrected scales for the geophysics logging suite, and positions of features may possibly be slightly different from coring depths of recovered sediments. In general, distinctive FMS resistivity features in both Pass \#1 and Pass \#2 within the 
carbonate platform portion of the borehole are approximately $0.5 \mathrm{~m}$ below the depth of the same resistivity feature in the geophysics logs. Therefore, the resistivity traces were shifted downward by $0.5 \mathrm{~m}$ (addition of $0.5 \mathrm{~m}$ to the "mbsf" depths) to allow direct calibration with the selected depth-reference scale of FMS Pass \#1. The naturalgamma-ray record used in the accompanying diagrams for Site 879 is from the NGT on the same FMS Pass \#1, so its depths should be consistent with depths of the FMS imagery processed by LDEO-BRG.

Regardless of the exact calibration of the various "corrected" depths, the thicknesses and spacing of all features will be identical among the borehole, the FMS imagery, and the other downhole logs.

\section{Processing of Formation MicroScanner Resistivity Imagery}

The FMS tool creates high-resolution images of the borehole by measuring the electrical resistivity contrast across an array of small electrodes (Ekstrom et al., 1986; Pezard and Luthi, 1988; Bourke et al., 1989; Molinie and Ogg, 1992b). The ODP FMS has four orthogonal pads containing 16 pad-mounted button electrodes that are pressed against the borehole. A single run of the ODP FMS provides approximately $25 \%$ coverage of the borehole circumference. Two runs were made in Hole $879 \mathrm{~A}$ to enable a maximum of $50 \%$ coverage of the borehole where traces did not overlap. Even though the borehole was very wide in many intervals, the slight tilt of the borehole from vertical generally allowed one or two FMS pads to be in contact with the sides. Resolution, processing, and interpretation of FMS imagery in shallow-water carbonate facies are discussed in Ogg et al. (this volume). The examples of FMS images reproduced in the figures in this report have been "static mode" processed over a 10 -m interval of the FMS record of Hole 879A (e.g., Fig. 3 is from an independently processed interval of 205-215 mbsf), implying that the 16 shades of gray have been linearly normalized between the highest value of resistivity (white) to the lowest value (black) occurring within that interval, and further enhanced using NIH Image software. Therefore, within each $10-\mathrm{m}$ interval, a particular shade of gray corresponds to the same relative resistivity, but that resistivity level may be represented by a different gray shade in the adjacent window. In order to interpret larger-scale features, the FMS data were also static-processed over 100-m intervals (see CD-ROM in Premoli Silva, Haggerty, Rack, et al., 1993).

\section{Geochemical Log Processing}

The geochemical records from the induced-gamma spectrum tool (GST) were converted by LDEO-BRG to relative elemental contributions by $\mathrm{Fe}$ (assuming an equal contribution by magnetite and hematite), $\mathrm{Ca}, \mathrm{Cl}, \mathrm{Si}, \mathrm{Su}, \mathrm{Ga}, \mathrm{Ti}$, and $\mathrm{H}$ (the last two elements were computed during processing), with corrections for hole diameter as recorded by calipers on the density tool (CALI on the HLDT) and on the FMS string ("C1" and "C2"). The relative ratios of these elemental factors are more useful for lithologic trends than the less accurate elemental values for direct computation of rock-chemistry.

\section{INTERPRETATION OF CARBONATE FACIES FROM DOWNHOLE LOGS}

Our goal in analyzing the various logs is to obtain a complete record of the history of depositional environments. The major carbonate textures and composite depositional facies (such as algalmicrobial mats) could generally be distinguished by their signatures on a combination of three logs: the spherical-focused resistivity log (SFLU), which measures the absolute resistivity of the borehole wall with a vertical resolution of about $75 \mathrm{~cm}$; the FMS microresistivity imagery, which indicates the "texture" and vertical successions at a subcentimeter scale, and the NGT record of the relative intensity of potassium, thorium, and uranium concentration. Within the upper- most $40 \mathrm{~m}$, where the suspended drill pipe prevented direct contact with the logging tools, the compensated neutron porosity (NPHI) log with 40-cm resolution (in open hole, but through drill pipe is probably much coarser resolution) enabled recognition of major changes in relative degrees of porosity. Use of a single type of log yielded more ambiguous interpretations. These log-facies signatures were developed from comparison of logs to intervals having good recovery of the lithologies and from application of logical relationships of carbonate depositional environments. In addition, the sediments recovered in each cored interval, although generally meager, provided important controls on the interpretation of the logging signals.

In contrast to surface exposures of carbonate platforms, the majority of the limestone cap of Takuyo-Daisan Guyot has been only partially cemented. Insignificant overburden (maximum of $150 \mathrm{~m}$ ) and lack of later meteoritic influence helped preserve the original granular relationships. Indeed, some pelletal grainstone and pelletized mudstone intervals were observed to have no apparent cementation, which also caused very low recovery and "washouts" during drilling. Above the basal drowning surface on the underlying clay weathering zone, there is a $\sim 15-\mathrm{m}$ interval where significant terrigenous clastic horizons occur. However, within the upper $150 \mathrm{~m}$, no noticeable terrigenous influx was present; therefore, the downhole logs can be interpreted entirely in terms of pure carbonate facies.

\section{Resistivity Log}

Resistivity of carbonate textures progressively increases from grainstone to mudstone as the porosity is steadily diminished (e.g., Asquith, 1979; Dorfman et al., 1990). Resistivity is also affected by the geometry of interconnected pore space. The recovered core material suggests that the initial texture of the limestone also influenced the degree of diagenetic cementation, with grainstone commonly less cemented than micritic mudstones. As a result, the corresponding responses of the resistivity and porosity tools are magnified by these changes in carbonate textures.

The low-porosity to high-resistivity relationship does not apply when an episode of penetrative early cementation has taken place because of possible subaerial exposure or hiatus in deposition. Such "surfaces" with underlying partial cementation are common in intervals that have pronounced development of "parasequences." In these cases, the shallower depth and presumably higher energy grainstonepackstone facies commonly underwent a greater degree of cementation and, therefore display an upward increase in resistivity. This high-resistivity upper bed of a cycle is overlain by a facies of very low resistivity representing the succeeding deepening phase.

\section{Natural-gamma-ray Log}

Natural-gamma-ray intensity (NGT or SGR) within the carbonate platform in Hole $879 \mathrm{~A}$ is mainly a monitor of the uranium concentration. The natural-gamma-ray logs have been reprocessed by LDEOBRG to correct for borehole size and type of drilling fluid, and to compute the relative abundance of uranium, thorium and potassium from the natural-gamma-ray spectrum. Some of these ratios may be affected by the rate of collection of logging data. However, influx of clays with radioactive thorium, and potassium are only important within the interbedded clastics and carbonates of Subunit ID. The primary component of total gamma-radiation in this hole is uranium.

Three distinct processes were observed to contribute to the variations in uranium natural-gamma-ray intensity within the overlying carbonate platform.

1. Uranium displays higher relative concentrations in algalcyanobacterial mats and oncolites because their reducing microenvironments are conducive to redox scavenging of uranium from seawater. Although this uranium concentration process is most effective for algal-cyanobacterial mats, it was also observed to be applicable to 
red-algal encrustations and concretions (rhodoliths). Such uranium concentrations were associated with cyclic shallow-lagoon, upwardshallowing successions within Hole 879A

2. Uranium can be concentrated during later diagenesis at the redox interfaces between relatively oxygenated and relatively reducing interstitial-water conditions. This redox enhancement was observed at the interfaces to organic-bearing clay-rich sediments (e.g., contacts within interbedded clastics and carbonates in Subunit ID) and also within the carbonate mud-rich transgressive sediments immediately overlying a surface of emergence or condensation. At these redox horizons, the uranium is precipitated in a narrow horizon on the oxygenated side of the boundary, in contrast to the more dispersed uranium concentrations associated with algal- and cyanobacterialrich facies.

3. Uranium is often enriched in limestone deposited in depositional environments in which organic matter or phosphate was originally present, because uranium from seawater is preferentially precipitated in relatively reducing conditions (Serra, 1985). Therefore, quiet-water carbonate facies, such as wackestone and mudstone, may display a higher natural-gamma-ray intensity than high-energy facies, such as grainstone. These lime-mud-rich sediments, which are also commonly bioturbated, probably retained a greater initial organic content during burial than the more aerated facies; therefore, uranium would be preferentially concentrated in the mud-rich facies. In this regard, minor peaks in uranium were observed to occur at levels interpreted as "maximum flooding surfaces," where the concentration of carbonate mud (and rare pelagic microfossils) and presumably fine organic material was at a maximum.

\section{Formation MicroScanner}

The FMS imagery was important to determine the texture of the different carbonate lithologies and cementation patterns at the centimeter scale and to compare fine-scale vertical trends in relative resistivity.

Grainstone facies typically display a uniform low-resistivity texture, which can be seen in the gray-scale imagery as a homogeneous, dark gray interval.

Packstone to wackestone facies generally had a more uneven, centimeter-scale resistivity, presumably resulting from differential abundance of carbonate mud and related extent of partial cementation during diagenesis. Therefore, the FMS imagery displays a more mottled appearance with irregular diffuse higher resistivity patches ("lightgray mottles"). In some wackestone-packstone, especially in recovered cores in lagoonal gastropod-pellet facies, significant leaching of the larger bioclasts has created a moldic porosity within a porous wackestone matrix. The corresponding FMS imagery displays a "medium-gray" moderate-resistivity background with abundant dark (leached) spots and some diffuse patches of preferential cementation.

In facies having microbial-enhanced concentrations of carbonate mud, such as algal-cyanobacterial-mat intervals or red-algae encrustations and coral-algal banks, horizontal lenses of high-resistivity material are distributed within a low-resistivity matrix. At Site 879, algal-cyanobacterial processes generally created oncolites, which are identified in the FMS imagery as 1-cm-diameter "spheres" of higher resistivity within a lower resistivity matrix.

Floatstone (mainly beds of storm-washed rubble) or boundstone beds (not observed in the FMS logs within this lagoonal setting) display a "blocky" texture of 10-cm-scale, rounded and sharp-bordered patches of contrasting resistivity. An interpretation of "storm bed" is assigned to distinct higher resistivity or "rubble" beds with sharp bases occurring within an otherwise homogeneous wackestonepackstone facies.

Our independent calibration of carbonate textures to the FMS imagery appearance is similar to the relationships observed in the logs in the carbonate platforms of the guyots drilled on preceding Leg 143 (Cooper et al., in press); however, there are some minor nomenclature and implied depositional environment differences. These differences are mainly the result of the calibration of the FMS imagery to shipboard descriptions of the same sediments. For example, the "mudstone with moldic porosity" facies of Cooper et al. (in press) displays the same FMS texture as our "bioclastic wackestone-packstone" classification. The sediments recovered in this facies consist of abundant bioclastic molds in wackestone-packstone that had undergone extensive diagenetic "chalkification." Therefore, it was not initially a mudstone, and we have tried to maintain the shipboard sedimentological nomenclature of the facies before extensive diagenesis.

\section{Compensated Neutron Porosity Log}

Porosity is measured according to the relative abundance of hydrogen in the formation. A radiogenic source of $4 \mathrm{MeV}$ neutrons bombards the formation, and the detector measures the number of returning scattered neutrons. The scattering cross section, or the rate at which neutrons are slowed, is nearly 100 times as large for hydrogen than for any other common elements. When neutrons dissipate sufficient energy by collisions with water molecules, and when they reach a low energy level of less than $0.025 \mathrm{MeV}$, they are captured and absorbed by such atomic nuclei as hydrogen and chlorine. Therefore, if porosity is high, a greater percentage of the neutrons is absorbed and fewer are returned to the detector. The effective resolution of this detector is approximately $40 \mathrm{~cm}$. The relative response of the neutron porosity log was observed to correlate well with the resistivity $\log$ when the borehole was not widened or obscured. However, unlike the resistivity tool, the neutron porosity tool was able to detect large-scale changes in porosity where a widened borehole attenuated the resistivity measurements or the suspended drill pipe prevented resistivity determinations. Therefore, in these intervals, the neutron porosity log was used as a proxy of relative degrees of cementation.

\section{Recovered Sediments}

Recovery was typically less than $5 \%$ of each cored interval (Premoli Silva, Haggerty, Rack et al., 1993). Recovery was highest when the cored facies consisted of homogeneous moderate-cemented carbonates or of clay-rich facies within Subunit ID. Neither wellcemented beds, which apparently shattered upon drilling, nor poorly cemented facies, which disintegrated under the drill, had significant recovery. Interbedded well-cemented and poor-cemented beds, such as occur in the shallow-water, upward-shoaling facies successions or parasequences, had recovery biased toward the uppermost wellcemented bed. Similar recovery biases were noted in the Leg 143 drilling of guyots (Cooper et al., in press). Unfortunately, an implication is that those intervals which contain a significant amount of vertical variation (hence of the most value to interpretations of changing depositional environments and possible sea-level changes) also have the lowest recovery of sediments to enable direct sedimentological interpretation of facies trends.

\section{Model of Depositional Facies}

The vertical succession of carbonate facies reflects changing depositional environments of wave energy (winnowing or deposition of carbonate mud), of ecological zones (algal mat, gastropod, etc.), and of relative water depth (emergent horizons, lime-mud enrichments, etc.). Interpretation of relative shifts of facies (e.g., lagoonward versus seaward, upward-shallowing versus deepening) requires a basic conceptual model of the original distribution and depositional environments of the various carbonate facies (Fig. 2).

Lagoonal facies present a particular problem because of the difficulty of identifying episodes of prograding coral-algal production ("carbonate factory") creating parasequences or of transgressive backstepping of seaward facies. Instead, a relative depth-facies interpretation can be made according to the relative proportion of lime-mud, 


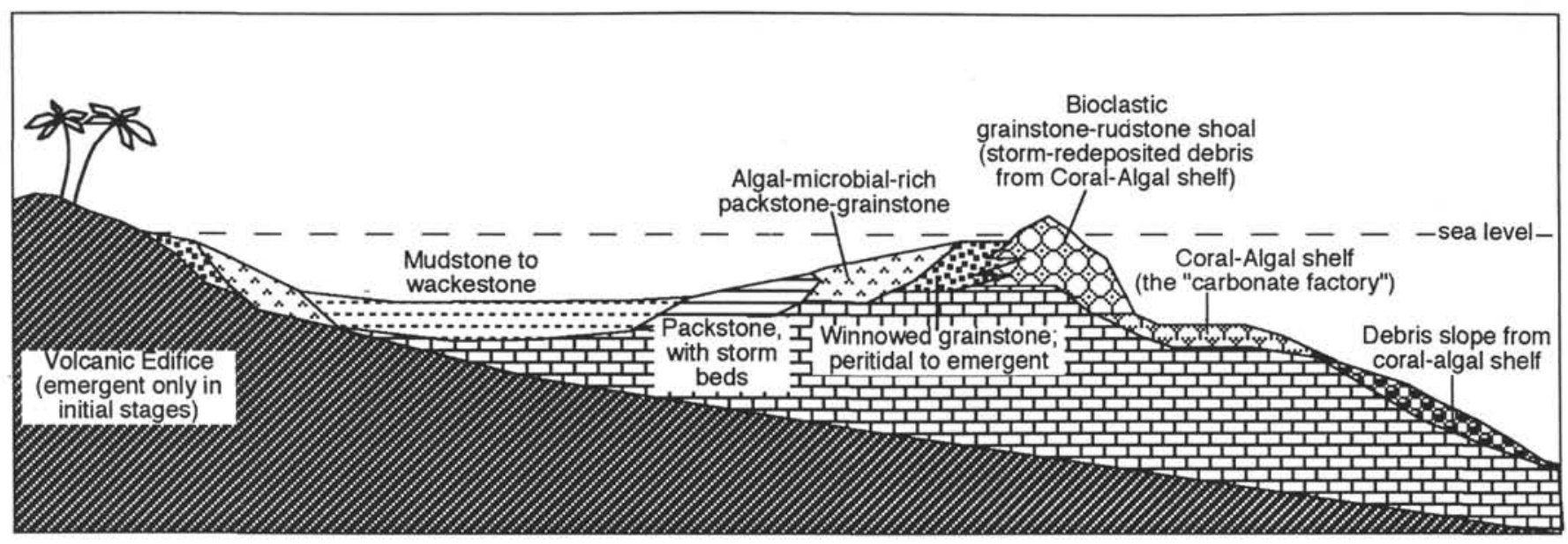

Figure 2. Idealized model of carbonate facies across a guyot platform. A quiet-water lagoon forms in the lee of shoal deposits of wave-redeposited bioclastic debris. Algal-cyanobacterial features and storm reworking occur preferentially in the shallower depths of the lagoon. A typical transgressive facies succession during initial submergence of the former volcanic island is wave-winnowed grainstone, algal-or oncoid-rich packstone and lime-mud-rich lagoonal sediments.

the relative importance of storm events disrupting sedimentation or washing in beds of coarser debris, and the biological assemblages. However, such "deepening" and "shallowing" trends can be obscured by changes in the degree of restriction of the lagoon floor from the open sea. A "quiet" lagoon facies might imply a greater degree of restriction, rather than a deeper water setting. Also, an increased abundance of storm-bed layers might reflect a greater proximity of grainstone-rudstone shoals, rather than a shallowing upward of the lagoon floor.

For placing the cored and logged facies of this Aptian-Albian atoll into a context of adjacent depositional environment belts, we used a simple model that combines relative mud content and biological assemblages. We used an idealized succession from the deep "lagoon" facies deposited in relatively quiet waters and/or distant from reefshoal barriers through the shallow "lagoon" facies or intertidal depths in the lee of barrier shoals to the "island" facies formed by storm accumulations from the seaward active carbonate-sediment production: (1) mudstone to wackestone with small benthic foraminifers; (2) wackestone-packstone with gastropods and miliolid foraminifers, which may contain cyanobacterial concretions; (3) packstone, which may contain layers of storm-redeposited or winnowed in situ grainstone or rudstone; (4) algal- and microbial-rich facies, which may contain algal and cyanobacterial concretions (rhodoliths or oncolites) in packstone-grainstone, and generally has an associated concentration of uranium; (5) winnowed grainstone of various bioclasts and foraminifers, or partially cemented packstone with fenestral features of possible intertidal or algal mat origin; (6) emergent grainstone-rudstone shoal or island of coarse storm-redeposited debris from the seaward carbonate production; and (7) coral-algal reef flat.

This conceptual model of relative lagoonal depth is partially based on comparisons with Tertiary atoll lagoon settings and Early Cretaceous carbonate seaways. However, the "lagoonal" facies may also be developed in interiors of platforms like the Bahama Banks which have a partial barrier (reefs and shoals) only on the windward side. It is not certain that these Cretaceous guyots had a true atoll morphology during much of their development. Therefore, "lagoon" is used here in a broad sense as a partially protected interior of the carbonate bank.

Algal-cyanobacterial mats and oncoids have a wide depth range. In Hole 878, these microbial features (often generalized as "algal" in the following descriptions, even though cyanobacteria play the major role) commonly are associated with a packstone-grainstones facies, which we generally interpret to represent a shallower depth than a lime-mud-rich facies. However, a transition from a skeletal wackestone with fenestrae features to an oncoid packstone would imply a deepening trend.
Carbonate platform facies of all geological ages typically have upward-shallowing cycles or parasequences superimposed upon larger scale trends. A parasequence is defined as "a relatively conformable succession of genetically related beds, or bedsets bounded by marine flooding surfaces or their correlative surfaces separating younger strata from older strata across which there is evidence of an abrupt increase in water depth" (Van Wagoner et al., 1990). These parasequences or upward-shallowing facies successions are typically of meter-scale thicknesses, and have recurrence periodicity similar to Milankovitch orbital-climate cycles, although the exact causes of the cyclicity is debated (e.g., reviews in Wilson, 1975; Tucker and Wright, 1990; Jones and Desrochers, 1992; Pratt et al., 1992; Plint et al., 1992).

Several intervals within Hole 879 A were dominated by repetitious, 3-m thick, cycles of upward-increasing resistivity sharply terminated to the lower resistivity base of the following cycle. These cycles were dominant when the depositional environment was "shallow lagoon to intertidal," and typically existed in the upward-shallowing suite of uncemented wackestone-packstone to oncoid-rich carbonate to relatively well-cemented packstone-grainstone. The associated FMS imagery and natural-gamma-ray characteristics indicated that some of the uppermost beds of some cycles are dense-cemented packstonegrainstone, which we interpret as a downward cementation episode associated with an emergence or condensation horizon. In these cases, the upward increase in resistivity is not caused by an increased carbonate mud component, but rather by an anomalous cementation level. In contrast, some upward-increasing resistivity cycles were interpreted as "upward-fining sequences" in the borehole logs into lagoonal facies of Cretaceous guyots drilled on Leg 143 (Cooper et al., in press).

The duration of individual parasequences in Hole 879A appears to be near the $100,000 \mathrm{yr}$ Milankovitch period of eccentricity modulation of precession. This Milankovitch cycle produces cyclic changes in global climate and ocean fertility and temperature (e.g., Molinie and Ogg, 1992a, 1992b). The predicted magnitude of these Milankovitch-induced oscillations of sea-level in nonglacial intervals is probably equivalent to the combined effect of ocean thermohaline volume changes $(\sim 0.1-10 \mathrm{~m}$, depending upon the magnitude of cyclical heating and cooling of deep ocean waters) and postulated changes in groundwater storage on the continents (up to 10-20 m; Revelle, 1990; Hay and Leslie, 1990; Plint et al., 1992). During stillstands or periods of falling sea level, these Milankovitch-cycle oscillations of global sea level will produce a series of stacked, condensed, upwardshallowing successions or parasequences. During long-term transgressions, these oscillations produce rapid upward pulses of sea-level interspersed with relative stillstands. 


\section{INTERPRETATION OF DEPOSITIONAL HISTORY}

The following depositional history of the carbonate facies integrates the independent observations from the cored sediments (typically $<50 \mathrm{~cm}$ of recovery from each $10-\mathrm{m}$ cored interval), the quantitative resistivity measurements, the variation in natural-gamma-ray intensities and associated uranium/thorium/potassium abundances, and the detailed FMS records of "textures" and vertical successions. Division of the lithologic succession into subunits was initially based upon the facies and nomenclature of shipboard-defined lithologic units. At Site 879 , the carbonate platform succession was denoted by the shipboard sedimentologists as lithologic Unit I with lettered subunits. The carbonate platform overlies a clay-rich weathering horizon (lithologic Unit II) developed on the volcanic edifice (lithologic Unit III). The continuous downhole logging records enabled improved resolution of the boundaries or transitions between these lithologic subunits (Table 1) and allowed additional subdivisions to be defined as coherent log-facies packets or as major parasequences (Fig. 1, back pocket). Summaries of the recovered lithologies of these subunits and details of the signatures and interpretation of possible depositional facies for the associated downhole logging subdivisions are compiled in the Appendix. All depths (mbsf) are according to the FMS "reference" $\log$ from LDEO-BGR.

Two important assumptions are required for this interpretation of the depositional history of Site 879. First, it is assumed that the logging characteristics and associated core recovery are representative of an unambiguous facies and associated depositional environment. The Shipboard Scientific Party (1993) compiled a preliminary depositional history of Takuyo-Daisan Guyot based mainly on the recovered facies. The broad outlines of their interpretation are similar to this study; however, the details differ significantly in many intervals because we have relied heavily on the high-resolution FMS imagery to identify facies characteristics where core recovery is meager or non-existent.

Second, it is assumed that the facies within Hole 879A reflect large-scale trends within the central portion of Takuyo-Daisan Guyot, rather than local shifts and isolated patterns of environments. The assumption of local versus general facies trends is particularly important for the interpretation that upward-shallowing parasequences reflect eustatic sea-level fluctuations rather than autocyclic behavior of the carbonate system. The interpretation of carbonate upward-shallowing cycles within isolated outcrops or logging data is debated (e.g., Osleger, 1991; Drummond and Wilkinson, 1993a, 1993b; Goldhammer et al., 1993; Grötsch, 1994). However, most regional studies have concluded that the major facies trends and sets of parasequences within a single outcrop are indicative of larger-scale patterns of facies shifts and carbonate sequence system tracts, rather than an artifact of random or autocyclic facies changes (e.g., Goldhammer et al., 1990; Van Wagoner et al., 1990; Osleger and Read, 1993; Gräfe and Wiedmann, 1993). Therefore, the major deepening or shallowing trends interpreted within Hole $879 \mathrm{~A}$ are considered to be indicative of broader facies trends within the central portion of the Takuyo-Daisan Guyot carbonate platform, and it is assumed that these trends provide a monitor of relative sea-level changes with respect to the platform.

\section{Volcanic Edifice Weathering and Submergence (226.5-164.4 mbsf; Lithologic Units III and II)}

The upper $24 \mathrm{~m}$ of the volcanic edifice (upper lithologic Unit III; 214-190 mbsf) consists of four basalt flows, averaging $1 \mathrm{~m}$ in thickness, interbedded with altered volcanic breccia. Contacts between basalt beds and volcanic breccia layers are sharp or have a rapid transitional zone (Fig. 3). Some of these basalt layers were possibly formed by intrusion of basaltic lava into soft, wet volcanic breccia (Shipboard Scientific Party, 1993).

A 26-m-thick clayey soil (lithologic Unit II; 190-164 mbsf) formed on the emergent volcanic island at Site 879 before submergence. This soil is the product of extensive weathering alteration of a volcanic breccia. There is a progressive upward increase in weathering intensity from altered breccia overlying the highest basalt bed to a homogenized, oxidized clay at the top, implying that most of this clayey soil was developed in situ. The upper portion of the highest basalt bed also appears to be partially altered. Presence of this thick soil indicates that (1) the volcanic edifice of Takuyo-Daisan Guyot underwent an extended period of tropical weathering, and (2) Site 879 was drilled on a subdued slope of the former island that was not subject to slope failure. A shallow slope is also consistent with the protection of the overlying marginal-marine facies from wave reworking.

The uppermost $2 \mathrm{~m}$ of the soil unit is an organic-rich clayey sandstone, representing a transitional facies to the overlying carbonate platform (Fig. 4). This clayey sand has grains of volcanics, carbonates, and coal; contains redox enrichments of uranium, potassium, and thorium; and is partially bioturbated. The depositional setting is envisioned as a marginal-marine marsh, that was protected from wave reworking by an offshore carbonate shoal.

\section{Shallow Platform Carbonates with Upward-shallowing Cycles (164.4-125.6 mbsf; Lithologic Subunits ID and IC)}

The lowest $39 \mathrm{~m}$ of the carbonate platform in Hole 879A consists of 12 major upward-shallowing cycles or parasequences developed in a quiet shallow-water lagoon sandwiched between a barrier-shoal complex and a weathered volcanic island. The core recovery is a semi-protected lagoonal facies dominated by bioturbated, gastropodrich skeletal peloid wackestone-packstone with variable terrigenous clay enrichment and with intervals containing abundant coated grains or intraclasts. No significant storm beds or other wave reworking were observed.

Each of the four upward-shallowing parasequences in the lower third of this succession (Subunit ID-1 through ID-4, 12 m total thickness) terminates in an enrichment in volcaniclastic clay and sand grains, derived from the adjacent weathered island. The next eight parasequences (Subunit IC-1 through IC-8, $27 \mathrm{~m}$ total thickness) consist of gastropod wackestone-packstone shoaling upwards to either an oncolite-bearing packstone and/or an episode of emergence. [Shipboard distinction of a unique volcanic-sand-rich "lithologic Subunit IE" was an artifact of sporadic and low recovery; therefore this subunit has been excluded; see discussion in Appendix.] The thickness of parasequences in both Subunits ID and IC averages $3.3 \mathrm{~m}$ and varies from $2.3 \mathrm{~m}$ to $4.4 \mathrm{~m}$. There is no apparent trend in parasequence thicknesses; however, the tops of the upper parasequences may be truncated by emergence.

Within the lower parasequence set (Subunit ID), the uppermost 20 to $30 \mathrm{~cm}$ of each cycle is a sandy clay-rich layer with very low resistivity and enrichments in thorium and potassium (Fig. 5). These layers are interpreted to be caused by progradation of clastics during a relative stillstand or lowstand of relative sea level. The overlying base of the next cycle is a packstone without detectable terrigenous clastics, indicating that a relative transgression had flooded the immediate source of this detrital input. The middle portion of each parasequence has the highest resistivity, indicating an increased carbonate mud content and/or a higher degree of cementation. The upper portion of each parasequence directly below the capping clay-enrichment horizon, has a lower resistivity, which may be caused by a partial enrichment in terrigenous clastics and/or decrease in carbonate mud content.

The highest significant clay is at the top of parasequence ID-4 at $152.7 \mathrm{mbsf}$ (Fig. 6). Above this level, core recovery and geochemical logs (e.g., natural-gamma ray spectra for identifying thorium) indicate that terrigenous detritus from the volcanic island was prevented from reaching this site for the remainder of the carbonate platform development.

The wackestone-packstone facies of the overlying Subunit IC contains dispersed grains within the carbonate facies. These grains were visually interpreted by the shipboard sedimentologists to be 
Orientation of FMS pad in borehole

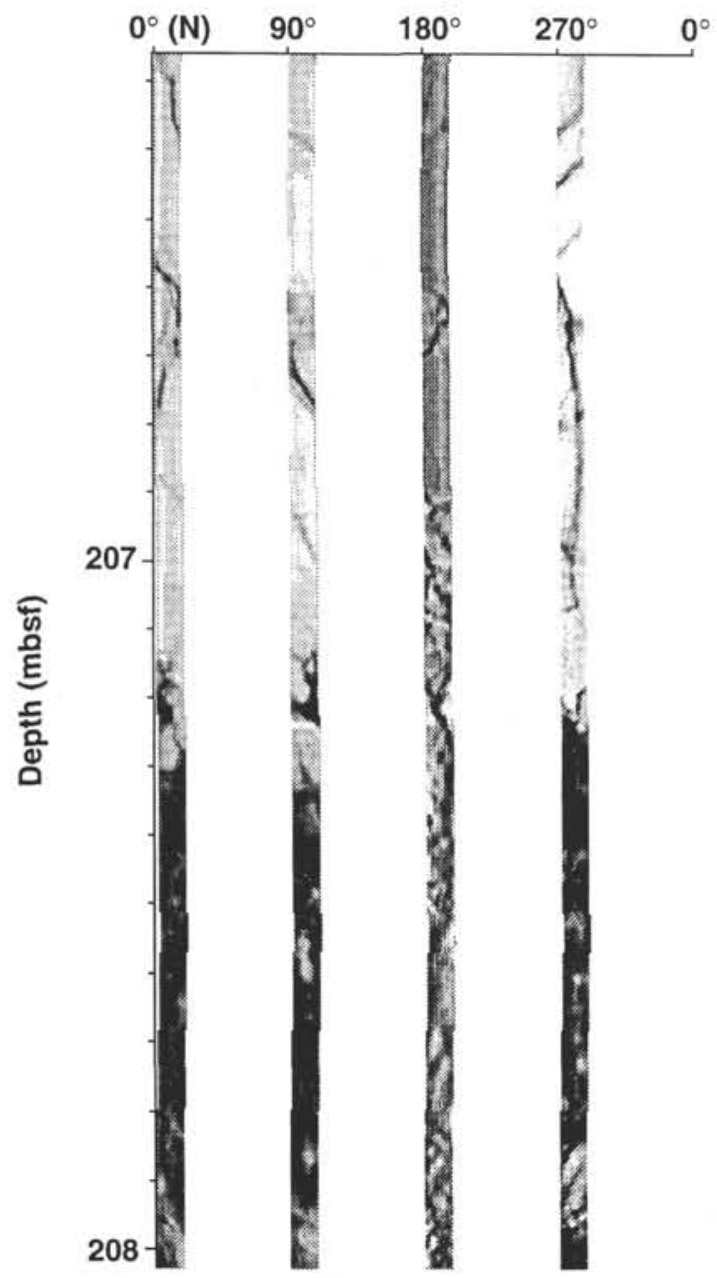

Figure 3. FMS image from the interbedded basalt and volcanic breccia of lithologic Unit III. This interval (206-208 mbsf; corresponding approximately to the base of Core 144-879A-22R) shows a fractured and veined bed of high-resistivity basalt overlying low-resistivity, clay-rich volcanic breccia. The contact is irregular, suggesting that the volcanic breccia sediment deformed during loading by the basalt flow. The volcanic breccia has a mottled appearance, which probably represents localized patches of less altered breccia or volcanic clasts. The gray-scale image has been static-processed within the interval from 205 to $215 \mathrm{mbsf}$; the associated resistivity values range from 40 $\Omega$-m (white on image) to $5 \Omega-\mathrm{m}$ (black on image). In this and all following FMS images, the high-resistivity beds are shown in white and low-resistivity beds are in black; the gray-scale contrast for relative resistivity has been maximized over the displayed image interval using NIH Image software; the orientation of the four FMS traces are clockwise around the borehole, with magnetic north on the left edge fixed by a borehole magnetometer in the FMS tool; the borehole circumference is approximately $1 \mathrm{~m}$.

altered basalt (Shipboard Scientific Party, 1993), although no supporting analyses were published and an associated abundance of clay was not observed. Some of these grains may be pumice fragments that have drifted to this site and been dispersed by bioturbation within the lagoonal sediments. In contrast to Shipboard Scientific Party (1993), we no longer consider the presence of these grains to be evidence of a continued influx of coarse volcanic detritus from an emergent volcanic island within the lagoon, although the sediments continue to have a minor component of organic carbon in TOC. This difficulty in using such grains for defining a Subunit, coupled with the important facies change at the top of the uppermost major parasequence

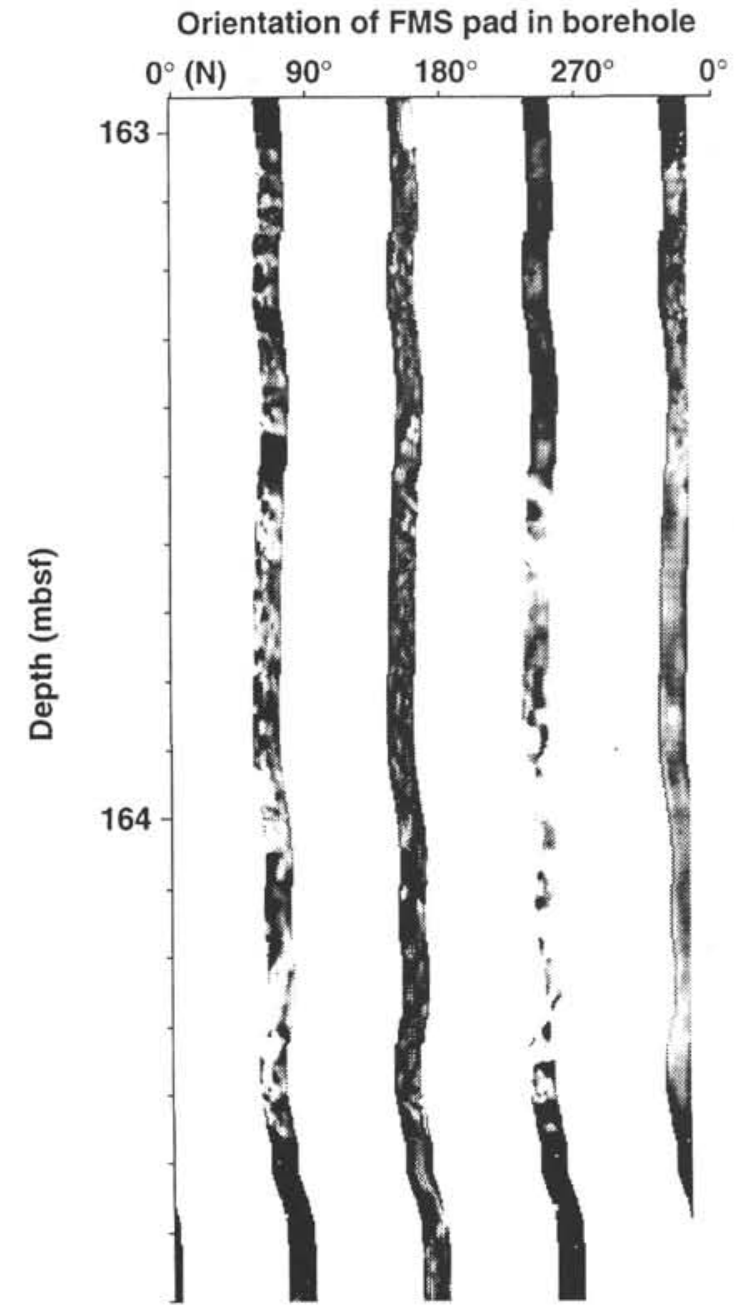

Figure 4. FMS image of the basal onlap of the carbonate platform (Subunit ID-1; late Aptian) on the weathered clay-rich volcanic edifice. This interval (163-165 mbsf; corresponding to the middle of Core 144-879A-18R) shows a mottled, high-resistivity, basal limestone with a sharp contact at $164.4 \mathrm{mbsf}$ to underlying low-resistivity, clay-rich sand. The limestone has a mottled texture on the 10-cm scale, consistent with a packstone-wackestone lithology. Some diffuse low-resistivity patches are subvertical and $5 \mathrm{~cm}$ long; these may be associated with bioturbation. The lowest meter of the limestone is relatively high resistivity, which may be the result of enhanced cementation at the redox contrast to the underlying organic-rich, clay-rich sand. The gray-scale image has been static-processed within the interval from 155 to $65 \mathrm{mbsf}$; the associated resistivity values range from $10 \Omega-\mathrm{m}$ (white on image) to $2 \Omega$-m (black on image). The blurring of the rightmost trace is caused by incomplete contact with the borehole wall. Format of FMS image is explained in Fig. 3.

(125.6 mbsf), led us to redefine the boundary between lithologic Subunit IC and IB (see expanded discussion in the Appendix).

Each of the parasequences in the upper set (Subunit IC) displayed an upward trend of increasing resistivity coupled with increasing uranium enrichment (Fig. 7). Oncoids are abundant in the recovered core pieces from this subunit; therefore, the increases in uranium content are interpreted to be associated with development of a cyanobacterial-rich facies with redox microenvironments. Unlike the algalrich facies associated with some shallow-water carbonate parasequences at the other guyots drilled during Leg 144 (e.g., Site 878 and Site 871), the FMS imagery in Hole 879A did not indicate any significant features that could be assigned to algal mats or encrustations. Maximum resistivity is attained at the top of each parasequence, which is sharply terminated in the low-resistivity base of the succes- 


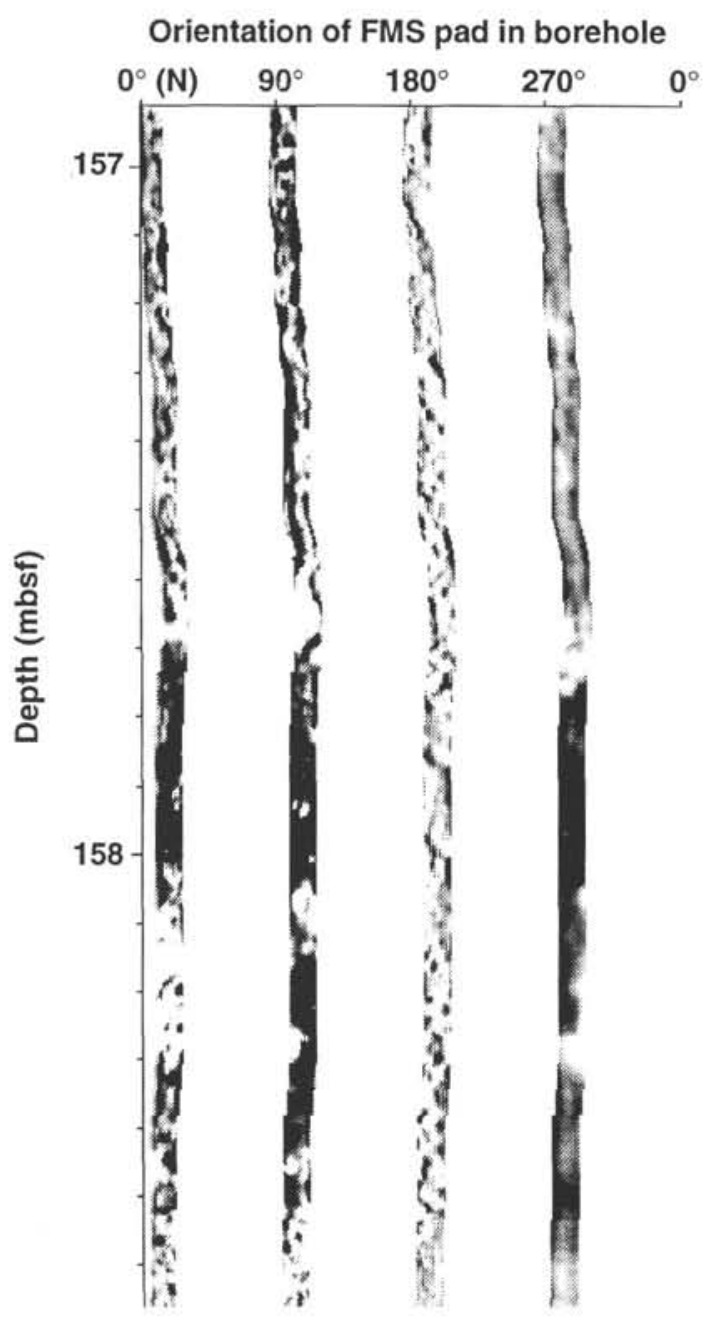

Figure 5. FMS image of clay-rich, prograding clastics terminating a 3-m-thick, upward-shallowing cycle and sharply overlain by the onlap of a carbonate-rich initial phase of the next cycle. This interval (157-159 mbsf; corresponding to the lower portion of Core 144-879A-17R) of cyclic shallow-lagoon facies spans the upper portion of logging Subunit ID-2 and the base of Subunit ID-3. The low-resistivity, $30-\mathrm{cm}$ band at $157.7-158.0 \mathrm{mbsf}$ is a bioturbated calcareous claystone. The mottled appearance in the resistivity of the adjacent limestones is mainly caused by a bioturbated packstone texture. The gray-scale image has been static-processed within the interval from 145 to $155 \mathrm{mbsf}$; the associated resistivity values range from $8 \Omega-\mathrm{m}$ (white on image) to $2 \Omega-\mathrm{m}$ (black on image). The lack of long-period resistivity contrast in one center FMS trace was a processing procedure failure, and the blurring of the rightmost trace is caused by incomplete contact with the borehole wall. Format of FMS image is explained in Fig. 3.

sive parasequence. This termination is interpreted to be an upwardshallowing and possible brief peritidal interval followed by a flooding surface and transgressive deepening. The rare presence of fenestral features in the limited core recovery also suggests that some parasequences included a phase of intertidal deposition.

A progressive upward trend in increasing resistivity of the capping beds of the parasequences suggests that a long-term upwardshallowing trend is superimposed upon the higher-frequency parasequences. The uppermost three parasequences (Subunits IC-6 through IC-8) are capped by beds of extremely high resistivity, which may have been formed by enhanced cementation during episodes of emergence. Episodes of emergence may have caused the observed yellowed staining and fenestrae in some core pieces. The low uranium

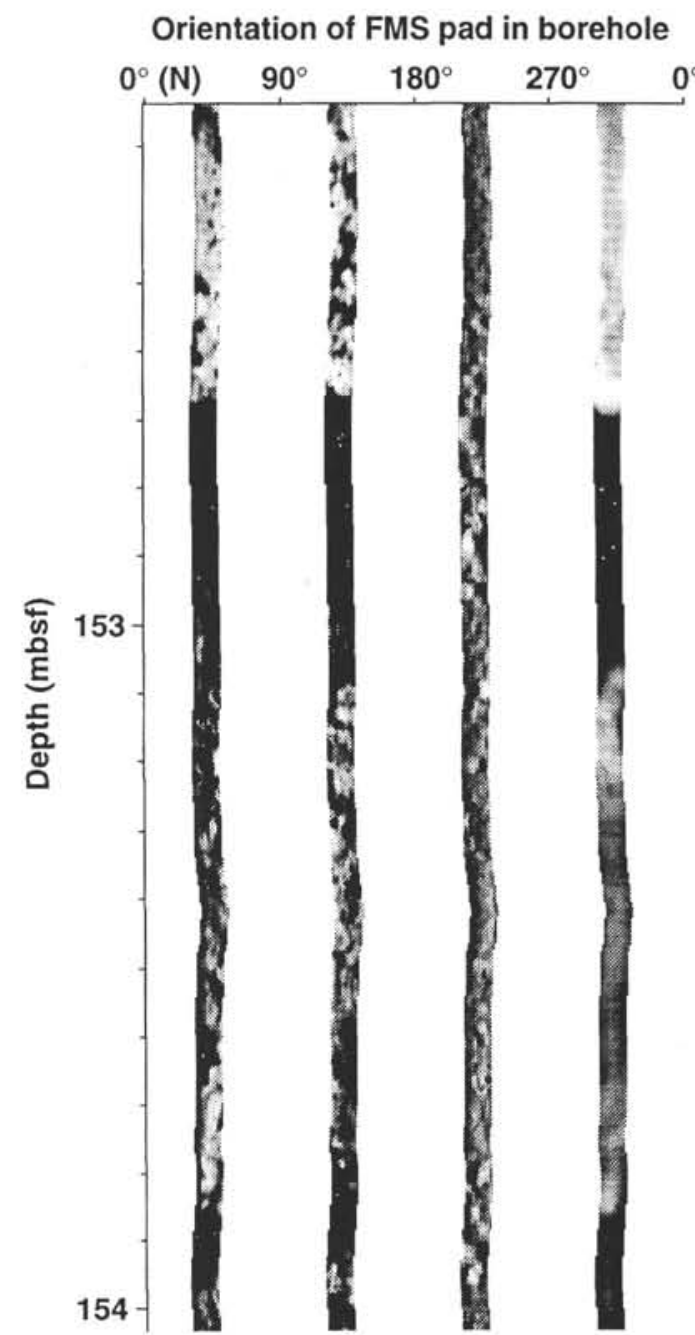

Figure 6. FMS image of the sharp basal contact at $152.7 \mathrm{mbsf}$ of Subunit IC on the clay-rich uppermost bed of Subunit ID. This interval (152-154 mbsf) of cyclic shallow-lagoon facies corresponds to the middle of Core 144-879A$17 \mathrm{R}$ of late Aptian age. The low-resistivity, $30-\mathrm{cm}$ band at $152.7-153.0 \mathrm{mbsf}$ is a clay-enriched, pyrite-rich, skeletal packstone that represents an increased terrigenous clay influx at the conclusion of an upward-shallowing cycle (Subunit ID-4). The mottled appearance in the resistivity of the adjacent limestones is mainly caused by a bioturbated packstone-wackestone texture. The gray-scale image has been static-processed within the interval from 145 to $155 \mathrm{mbsf}$; the associated resistivity values range from $8 \Omega-\mathrm{m}$ (white on image) to $2 \Omega-\mathrm{m}$ (black on image). The lack of long-period resistivity contrast in one center FMS trace was a processing procedure failure, and the blurring of the rightmost trace is caused by incomplete contact with the borehole wall. Format of FMS image is explained in Fig. 3.

content of these uppermost parasequences suggests that oncolite concentrations are not as important as in the underlying parasequences.

In the tropical regions of the Pacific during the Mesozoic, prominent cycles of productivity have been correlated to the eccentricity components ( 100 k.y.; 400 k.y.) of Milankovitch climate-oceanographic cooling cycles (e.g., Molinie and Ogg, 1992a, 1992b; Ogg et al., 1992). This eccentricity modulation of precession should also cause overall cooling-warming cycles of the deep ocean, thereby creating rises and falls of eustatic sea level (e.g., Revelle, 1990). If the midCretaceous shallow-water carbonate parasequences of $3.3 \mathrm{~m}$ thickness in Hole 879A also correspond to such 100 k.y. Milankovitch cyclicity in eustatic sea level, then the implied net accumulation rate 
is approximately $33 \mathrm{~m} / \mathrm{m} . y$. after compaction. Under these assumptions, the implied total duration of the 12 cycles comprising Subunits ID through IC is 1.2 m.y.

Subunit ID and the majority of Subunit IC are interpreted to be a transgressive and highstand systems tract. The presence of emergent levels in the upper parasequences of Subunit IC suggests a reduced accommodation space. This change in parasequence character could be interpreted as the occurrence of a sequence boundary (rapid relative shallowing of facies) at the base of the lower major emergence (upper part of Subunit IC-6, or about 135 mbsf).

\section{Deepening to a Lagoonal Environment, Followed by Shallowing into Peritidal Cyclic Sedimentation (125.6-88.0 mbsf; Logging Facies Subunits IB-1 through IB-4)}

The parasequence suite of Subunit IC was terminated by a major transgressive deepening (125.6 mbsf). The overlying $24 \mathrm{~m}$ is dominated by poorly cemented foraminifer-gastropod wackestone with no indications of significant wave- or storm-reworking (Subunits IB-1 through IB-3). However, interpretation of facies is hindered by the lack of core recovery and by the widened borehole which limits FMS imagery to the wall contact of a single pad.

The lower portion of Subunit IB is a subdued cycle of resistivity (Subunits IB-1) that resembles the general character of resistivity trends in the underlying parasequences. This lower sharp-topped cycle may be an upward-shallowing parasequence superimposed on an overall deepening phase. Its expanded thickness of $5.6 \mathrm{~m}$ is consistent with a greater accommodation space created by the overall transgressive trend. If this basal parasequence represents the $100,000 \mathrm{yr}$ periodicity, as was tentatively assumed for the upward-shallowing cycles in Subunit IC, then the initial rate of transgressive deepening was about $2 \mathrm{~m}$ per $100,000 \mathrm{yr}$ in addition to any increase in the minimum depth attained by the upward-shallowing cycle.

Resistivity and neutron porosity variations in Subunits IB-2 and IB-3 suggest possible cyclic trends with about $4 \mathrm{~m}$ thicknesses, but details could not be resolved. The poorly cemented nature of this interval is similar to intervals of peloid packstone accumulations observed in other guyot "lagoon" settings.

At about 102 mbsf is a rapid shift to an assemblage of shallowwater facies, that includes bioclastic rudstone, redeposited skeletal grainstone with coral fragments, and fenestral wackestone (Subunit IB-4; $14 \mathrm{~m}$ thickness). FMS, resistivity, and porosity logs suggest approximately four main cycles in physical properties, with uranium concentrations coinciding with portions of these cycles. Some of these cycles have a sharp upper surface, similar to the parasequences of Subunit IC. Therefore, the core recovery and logging observations indicate that this interval consists of four main parasequences in shallow-water to peritidal facies. However, there is no evidence of periods of significant emergence within the shallow-water parasequences. The rapid onset of this shallow-water facies may indicate a sequence boundary, and the succession ends with a rapid transgressive transition into the overlying deeper water facies.

\section{Minor Second Deepening Episode, Deposition in a Protected Lagoon (88.0-39.0 mbsf; Logging Facies Subunits IB-5 through IB-8)}

A high-porosity, poorly cemented facies at 83-88 mbsf (Subunit IB-5; $5 \mathrm{~m}$ thickness) is interpreted as a foraminifer peloid packstonegrainstone. A moderate uranium concentration suggests the presence of oncolites. The overlying low-porosity, low-resistivity facies (Subunit IB-6;22 m) was not recovered during coring, but is probably a compacted peloidal wackestone-packstone. A 9-m interval of fluctuating porosity (Subunit IB-7) is interpreted as possible cycles of packstone-wackestone. There are no indications of higher-resistivity beds of possible storm- or wave-reworking; however, this interval

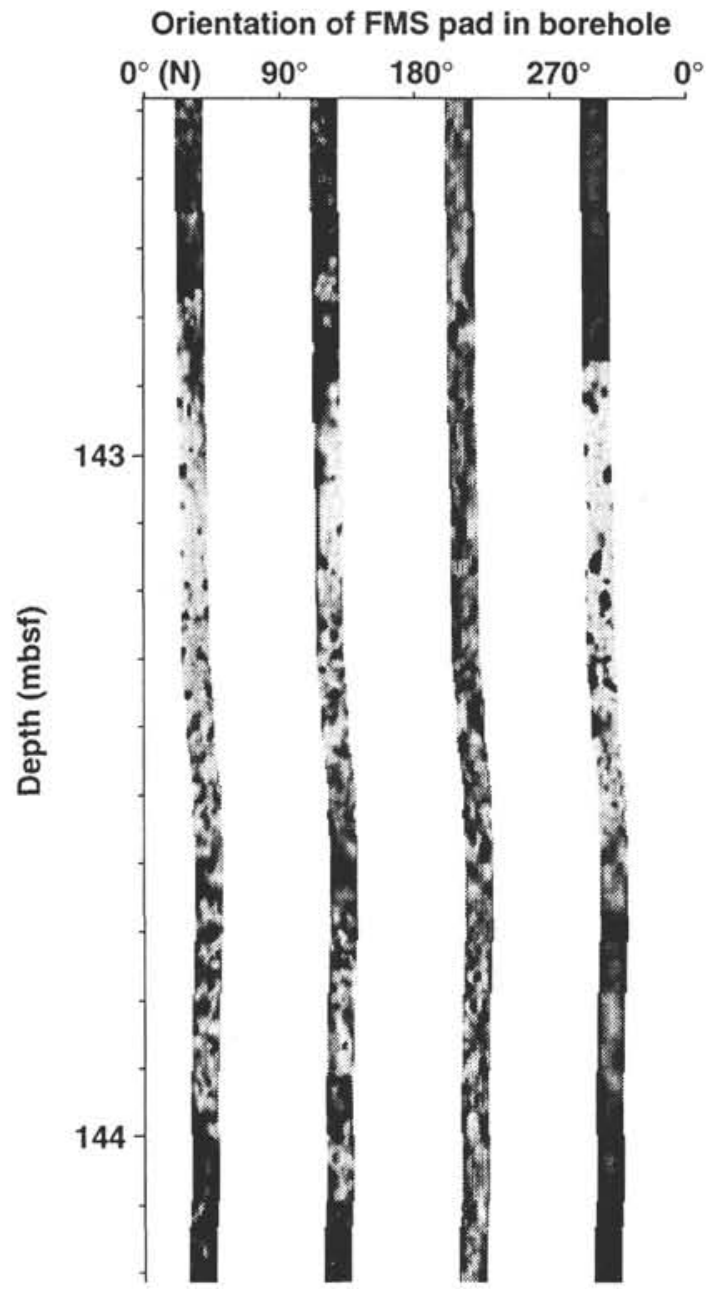

Figure 7. FMS image of the top surface ( $142.9 \mathrm{mbsf})$ of the well-cemented uppermost bed of an upward-shallowing cycle (Subunit IC-3) and the overlying low-resistivity basal facies of the next cycle (Subunit IC-4). This interval (142-144 mbsf) of cyclic shallow-lagoon facies corresponds to the upper portion of Core 144-879A-16R of late Aptian age. The limestones at the base (below $143.5 \mathrm{mbsf}$ ) and the top (above $142.9 \mathrm{mbsf}$ ) of this image display $\sim 1$-cm-diameter "balls" of medium resistivity, which are associated with sustained concentrations of uranium in the natural-gamma-ray intensity log and probably correspond to oncolites in wackestone-packstone. The upper surface on the well-cemented layer at 142.9 mbsf has "voids" that may be solution molds formed during an episode of emergence. This bed probably corresponds to lithology containing yellow-stained burrows and cavities with manganese dendrites recovered in interval 144-879A-16R, 68-94 cm. The gray-scale image has been static-processed within the interval from 135 to $145 \mathrm{mbsf}$; the associated resistivity values range from $15 \Omega-\mathrm{m}$ (white on image) to $2 \Omega-\mathrm{m}$ (black on image). The lack of long-period resistivity contrast in one center FMS trace was a processing procedure failure. Format of FMS image is explained in Fig. 3.

was also not recovered. The interpreted progression from a relatively granular to a more lime-mud-rich facies is consistent with a deepening trend from the shallow conditions of Subunit IB-4 through moderate-depth oncolite-bearing sediments of Subunit IB-5 to protected lagoon facies of Subunits IB-6 and IB-7.

The uppermost facies in Subunit IB is a very high-porosity, lowresistivity facies (Subunit IB-8; $13 \mathrm{~m}$ thickness). The physical log characteristics combined with the core recovery (only $15 \mathrm{~cm}$ ) indicates that this interval is poorly cemented and micritized, foraminiferpeloid grainstone with intervals of packstone (Fig. 8). This contrast to 


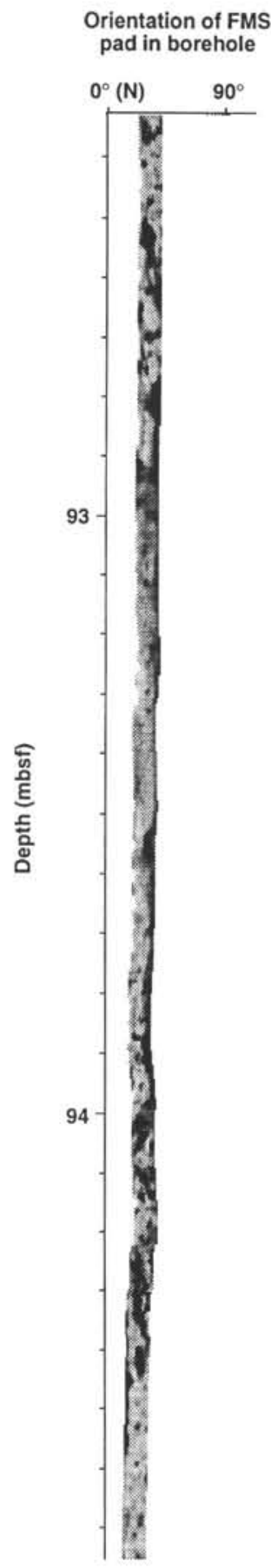

Figure 8. FMS image of shallow-water to peritidal facies of Subunit IB-4. This interval (92-95 mbsf) corresponds to recovery in Cores 144-979A-10R and $-11 \mathrm{R}$ of skeletal grainstone, fenestral wackestone, and gastropod-bivalve rudstone with moldic porosity. The beds of varying bulk resistivity (Fig. 1) may correspond to shallowing-upward episodes. A widened borehole prevented contact of the other three FMS pads. This image has enhanced contrast to illustrate the moldic porosity within the more homogeneous grainstone facies.

the underlying lime-mud-rich lagoonal facies suggests either a transition to shallower depths and/or increased exposure to open-marine conditions. Asymmetric calcite cements may be evidence of temporary intertidal conditions.

Subunits IB-5 through IB- 8 represent transgressive and highstand systems tracts. We have redefined the upper boundary of Subunit IB to be the base of a distinctive low-porosity and enhanced-uraniumcontent bed at 39 mbsf, which is considered to represent a rapid transition from the relatively deep-water lagoon environment to the onset of a succession of relatively shallow-water parasequences. This new definition contrasts with the shipboard definition, which was based on negligible core recovery (see discussion in the Appendix).

\section{Shallowing to a Wave-Reworked Depositional Environment, then Terminal Drowning (39.0-0.0 mbsf; Lithologic Subunit IA)}

A 4-m-thick, low-porosity, moderate-uranium bed (Subunit IA-1) coincides with recovery of an assemblage of oncolite foraminifer grainstone, fenestral wackestone and skeletal-oncoid floatstone (Core 144-879A-5R). This interval marks a rapid shift from a lagoonal facies to an oncoid-rich shallow-water to peritidal depositional environment.

The next $31 \mathrm{~m}$ (Subunit IA-2) is characterized by three alternations of a high-porosity lithology overlain by a low-porosity facies. The associated core recovery indicates that these alternations are accumulations of wave-redeposited coral- and bivalve-rich floatstone (low-bulk-porosity beds) and of partially winnowed lagoonal-type sediment of gastropod-rich peloid packstone to grainstone (highbulk-porosity beds). There may have been episodes of emergence associated with some of the low-porosity floatstone beds, but neither the limited core recovery nor attenuated logging data obtained through the drill pipe show unambiguous evidence of major exposure.

This interval, the only depositional environment at Site 879 dominated by storm- and wave-reworking, indicates onset of open-marine to storm-deposited shoal conditions. A rapid shallowing marks the base of Subunit IA-1 (39 mbsf) as a barrier-shoal complex prograded over the lagoonal facies of upper Subunit IB. This shoal complex is flanked by peritidal margins with algal-cyanobacterial mats. The rapid shallowing episode indicates a sequence boundary, and the overlying barrier-shoal is considered to be the equivalent of a lowstand systems tract.

Subunit IA represents the upper portion of the elevated south perimeter rim, rising approximately $70-80 \mathrm{~m}$ above the interior platform surface. It was expected that this rim was a constructional feature produced directly by an active seaward "carbonate factory." However, neither the available logging data nor the core recovery indicates any reef-type open-marine bioherm feature. Instead, the algalcyanobacterial-rich Subunit IA-1 and storm-debris-rich Subunit IA-2 are interpreted as $35-\mathrm{m}$ of shoal deposits of bioclastic sand and coarse rubble interspersed with algal-cyanobacterial mats and possible brief episodes of emergence. These deposits indicate a major process forming the south perimeter ridge of Takuyo-Daisan Guyot was a series of shoals of redeposited bioclastic material derived from a seaward carbonate factory. Therefore, a portion of the perimeter rim is analogous to the modern atoll island necklaces constructed by coral-floatstone accumulations washed lagoonward by constant waves and periodic storms. The drilling on Leg 144 did not provide any evidence for a constructional outer reef at Takuyo-Daisan Guyot, but it is possible that some minor bioherm deposits may have existed on the seaward margins of the perimeter ridge.

The highest sediments in Hole 879A are a 4-m-thick, winnowed, gastropod-peloid packstone to coquina (Subunit IA-3) capped by a scoured silica- and phosphate-rich hardground. This assemblage is from bioclastic sand shoals in a high-energy setting, but there are no indications of emergence. The terminal facies of the carbonate platform at this perimeter ridge site appears to be deposited initially in a short-lived "lagoon" setting (peloid- and gastropod-rich), followed by or coincident with later winnowing of finer-grained components. Van Waasbergen and Winterer (1993) postulate from detailed bathymetric surveys that Takuyo-Daisan Guyot experienced an episode of karstic erosion leading to formation of the rimmed-lagoon geomorphology and apparent breaks within the perimeter rim. However, there is no evidence from the logging or core recovery in Hole 879A 
Table 1. Lithologic subunit boundaries in Hole 879A assigned from FMS imagery and other borehole logs compared to shipboard assignments from core recovery.

\begin{tabular}{|c|c|c|c|c|c|}
\hline $\begin{array}{l}\text { Unit or } \\
\text { subunit }\end{array}$ & $\begin{array}{l}\text { Lithology } \\
\text { (brief summary) }\end{array}$ & $\begin{array}{c}\text { Base in } \\
\text { borehole } \\
\text { (mbsf) }\end{array}$ & $\begin{array}{l}\text { Thickness } \\
(\mathrm{m})\end{array}$ & $\begin{array}{c}\text { Shipboard } \\
\text { assignment } \\
\text { (core, section, } \\
\text { interval [in } \mathrm{cm}] \text { ) }\end{array}$ & $\begin{array}{c}\text { Shipboard } \\
\text { estimate } \\
\text { of base } \\
\text { (mbsf) }\end{array}$ \\
\hline IA & $\begin{array}{l}\text { Coral-mollusk rudstone and gastropod-peloid packstone-grainstone; } \\
\text { capped by phosphatic Fe-Mn crust }\end{array}$ & 39.0 & 39.0 & $6 \mathrm{R}-1,0$ & 44.3 \\
\hline IB & $\begin{array}{l}\text { Foraminifer-gastropod packstone; minor interval of skeletal grainstone } \\
\text { and algal-fenestral wackestone }\end{array}$ & 125.6 & 85.6 & $16 \mathrm{R}-1,0$ & 140.8 \\
\hline IC & Skeletal wackestone-packstone with algal oncolites; cyclic to deposition & 152.7 & 27.1 & $17 \mathrm{R}-1,18$ & 150.6 \\
\hline ID & Gastropod-peloid packstone interbedded with detrital volcaniclastics & 164.4 & 11.7 & $17 R-2,0$ & 151.9 \\
\hline IE & [Combined with new definition of Subunit ID] & & & $19 \mathrm{R}-1,0$ & 169.7 \\
\hline П & Claystone formed from weathered volcanic breccia & 190.0 & 25.6 & $21 \mathrm{R}-2,76$ & 191.0 \\
\hline III & Volcaniclastic breccia interbedded with basalt flows & $>226.5$ & $>36.5$ & $\begin{array}{c}24 \mathrm{R}-1,105 \\
\text { (base of hole) }\end{array}$ & $>226.5$ \\
\hline
\end{tabular}

of significant extended subaerial exposure at this rim site before the final submergence.

\section{DISCUSSION AND CONCLUSIONS}

\section{Depositional Sequences and Short-period Cyclicity}

The Aptian to Albian carbonate platform series at Site 879 can be interpreted as a series of major depositional sequences. The transgressive to early highstand systems tract of each depositional sequence consists of lagoon facies of foraminifer- and gastropod-rich wackestone and packstone without significant storm-bed layers. The latehighstand to lowstand systems tracts are characterized by shallowlagoon to intertidal facies with $\sim 3$-m-thick, upward-shoaling cycles. The transitions between the highstand deep-lagoon to the cyclic shallowlagoon facies are relatively abrupt and may correspond to "sequence boundaries" of falling relative sea levels. Similarly, the transitions between shallow-lagoon to deep-lagoon facies seem to incorporate only one or two upward-shallowing cycles of intermediate-depth character (e.g., the deepening transitions of Subunits IB-1, IB-5, and IA-1).

The upward-shoaling cycles have variable character within the different shallow-lagoon facies (Figs. 3-6). The lower four cycles, which comprise Subunit ID, consist of a carbonate-rich transgressive unit followed by a prograding clay-rich terrigenous unit. Further transgressive submergence of the volcanic island prohibited influx of significant terrigenous debris to this site. Within the eight main upward-shallowing cycles comprising the succeeding Subunit IC, the lower cycles have gastropod wackestone-packstone grading upward to oncolite-bearing packstone, and the upper cycles appear to incorporate terminal episodes of emergence. The cyclicity of Subunit IB-4 is less pronounced, but it appears to incorporate gastropod- and bivalve-rich packstone, intervals of algal-cyanobacterial enrichment, and levels of intertidal sedimentation. Subunit IA-1 is a rhodolith-rich cycle, and the following Subunit IA-2 is characterized by major episodes (noncyclic?) of storm-redeposited, coral-bivalve floatstone onto a shallow-lagoon environment or forming bioclastic sand shoals.

The lowest depositional sequence (Subunits ID and IC, 125.6$164.4 \mathrm{mbsf}, 38.8 \mathrm{~m}$ thick) onlaps a 26 -m-thick clay-rich weathering zone on volcanic breccia (Fig. 2) and contains a total of 12 cycles. In the lower $12 \mathrm{~m}$, these cycles are a mixture of transgressive-carbonate and prograding-clastic facies. In the upper $27 \mathrm{~m}$, the cycles are developed in oncoid-rich to emergent shallow-lagoon facies. The basal onlap of lagoonal sediments onto the volcanic island may not necessarily represent a formal "transgressive systems tract" associated with a eustatic rise of sea level; rather, it may represent the process of steady thermal subsidence of the seamount during a relative stillstand of sea level. The lowest sediments of the carbonate platform in Hole $879 \mathrm{~A}$ indicate a protected "lagoon" environment, either caused by the overall topography of the volcanic basement or the presence of offshore barrier shoals or "reefs." With continued subsidence, the contribution of clay-rich sediments from the island is diminished. The seismic profiles of Takuyo-Daisan Guyot indicate that a volcanic peak must have been emergent from the lagoon waters throughout deposition of the carbonate platform successions. However, core recovery and geochemical logs indicate that any clay-rich sediments shed by this volcanic island were apparently trapped close to its shore. Throughout most of its history, Takuyo-Daisan Guyot probably resembled the present islands of Truk Lagoon, where a rimmed lagoon with sedimentation dominated by foraminifer- and lime-mud-rich carbonates encloses remnant volcanic islands.

The second depositional sequence (Subunits IB-1 through IB-4, 88.0-125.6 mbsf, $37.6 \mathrm{~m}$ thick) has a 24-m-thick deep-lagoon, foraminifer-pellet packstone followed by a 14 -m-thick interval with four main cycles of shallow-lagoon to intertidal or emergent facies. The deepening episode at 88 mbsf appears to be relatively minor, but it does result in a return to an extended interval of poorly cemented sediments dominated by lagoonal facies.

The third depositional sequence (4-88 mbsf, $84 \mathrm{~m}$ thickness) begins with 49-m-thick, transgressive and early highstand systems tract of quiet lagoon facies (Subunits IB-5 through IB-8). This quietlagoon facies includes a $22-\mathrm{m}$ zone of an unusual low-porosity, but uncemented lithology (Subunit IB-6), which is interpreted to be compacted pelletal lime mud. This uncemented zone is approximately coincident with the lower portion of the topographic rim feature at this site, and an alternate origin based on the karst solution-basin model of Van Waasbergen and Winterer (1993) for the rimmedlagoon geomorphology may be a large solution cavern that infilled with fine carbonate mud during later submergence. However, there is no recovery within this interval, and the widened borehole prevented FMS imagery.

The late highstand to lowstand systems tract of the third depositional sequence begins with a thin oncolite interval (Subunit IA-1). This shallow-lagoon facies is followed by an unusual series of four main episodes of winnowed, gastropod-rich facies interbedded with redeposited coral-rich floatstone (Subunit IA-2). These reworked deposits may represent the Cretaceous equivalent of storm-debris accumulations that construct the island rings of modern atolls; such deposits may have also played a major role in constructing the rimlagoon geomorphology of Takuyo-Daisan Guyot. However, the origin of the 70-m-high southern rim cannot be determined from the limited logging data and core recovery, although the drilling results did not provide any evidence for either a wave-resistant bioherm construction or a solution edge-effect during prolonged subaerial exposure. The highest $4 \mathrm{~m}$ in Hole $879 \mathrm{~A}$ is a winnowed, gastropodrich, peloid grainstone-coquina (Subunit IA-3), which may represent bioclastic sand shoals reworked during the initial transgressive stages of final submergence of the guyot.

\section{Age and Possible Correlation of Depositional Sequences}

In Hole $879 \mathrm{~A}$, the carbonate platform exhibits three main upwardshallowing successions, followed by a final submergence (Fig. 9). The lithostratigraphy derived from the cores and logs indicates no 


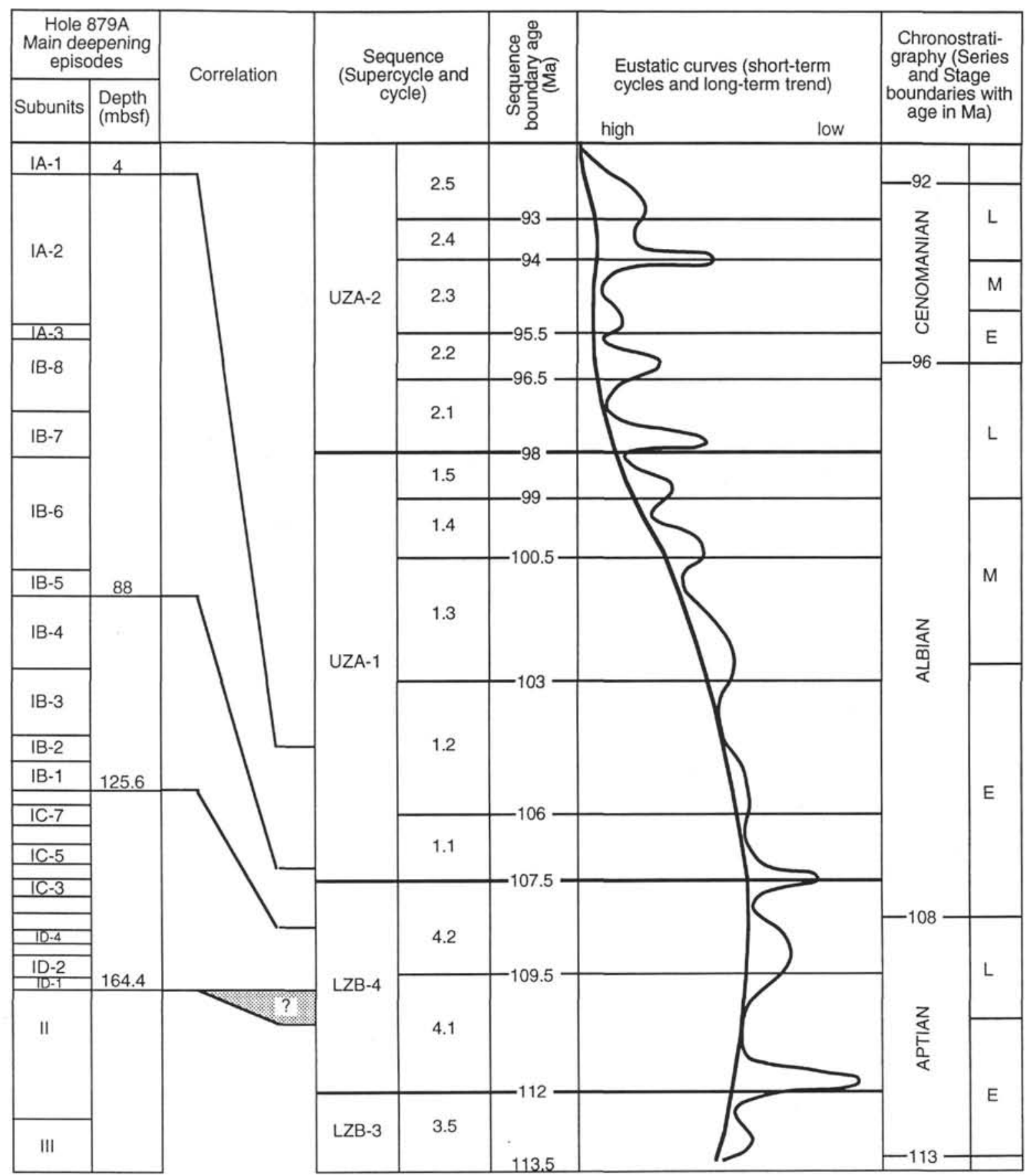

Figure 9. Major deepening episodes in Hole 879A and possible correlations to major transgressions in the Aptian-Albian portion of the eustatic sea-level curve compiled by Haq et al. (1988; Table 2). Correlations of deepening episodes in Hole 879A are constrained by the late Aptian age of the lower portion.

apparent major episodes of emergence, nondeposition, or erosion. Thus, it would appear that these three major upward-shallowing successions represent continuous sedimentation responding to a fluctuating relative sea level.

The sequence stratigraphy charts of Haq et al. (1988) subdivide the stratigraphy of coastal onlap and upward-shallowing successions into "sequences" defined as strata deposited between maximum rates of relative sea-level fall ("sequence boundaries"). In sedimentary outcrops or boreholes, it is generally easier to identify the transgressive deepening termination of an upward-shallowing succession, rather than the "Exxon"-type sequence boundary.
The sequence stratigraphy charts of Haq et al. (1988) have been critically reviewed by many geologists, who typically find defects with portions of the schematic time scale and the lack of publication of supporting field and seismic data. However, these charts provide a useful summary of major facies changes on the Northwest Europe craton. If these sea-level excursions are caused by eustatic sea-level fluctuations, then these events may be recorded on Pacific guyots. The Aptian-Albian portion of the Haq et al. (1988) sequence chart is based upon interpretations of various French sections including Apt (stratotype of Aptian stage), Gargas (Gargasian regional stage, equivalent to middle Aptian), and Aube (type region of Albian). 
Do the three major upward-shallowing cycles in Hole $879 \mathrm{~A}$ have corresponding coeval sea-level excursions in the Haq et al. (1988) interpretations of the French sequence stratigraphy? A reliable correlation requires precise biostratigraphic controls on the carbonate platform successions. Unfortunately, different ages for the major cycles in Hole 879A can only be derived from the different microfossil assemblages.

The lowest transgressive to lowstand systems tract (Subunits IDIC) contains an early-late Aptian nannofossil assemblage (middle of Parhabdolithus angustus Zone (NC7; Cores 144-879A-17R and $-18 \mathrm{R})$ and a possible late Aptian planktonic foraminifer assemblage (Cores 144-879A-16R to -18R; Shipboard Scientific Party, 1993; Erba, this volume). The nannofossil assemblage indicates that the lower portion of the carbonate platform in Hole 879A has a similar age as the base of the second carbonate platform on MIT Guyot (Core 144-878A-41M; Erba, this volume). However, the identification of benthic foraminifers in Cores 144-879A-16R and above (?Vercorsella scarsellai and Trocholina odukpaniensis) suggests a ?middle Albian to late Albian age (Arnaud Vanneau, this volume).

The third deep-lagoon facies and upward-shallowing succession has a different and diverse benthic foraminifer assemblage (recorded in Core 144-879A-6R and higher), including the only orbitolinid foraminifers in Hole 879A. Subunit IA was initially interpreted to be "late Aptian or Albian" (Shipboard Scientific Party, 1993), but further study of the benthic foraminifers now suggests a late Albian age (Arnaud Vanneau, this volume).

It is not possible to reconcile the late Aptian nannofossil assemblage in Core 144-879A-17R with the ?middle Albian benthic foraminifer assemblage from overlying Core 144-879A-16R, because the overall facies and parasequence pattern on the various logs appear to indicate continuous sedimentation. The ?late Aptian planktonic foraminifers from Core 144-879A-16R are also in disagreement with the benthic foraminifers. To confound the problem, a reported $\mathrm{Ar} / \mathrm{Ar}$ radiometric date of $101.8 \mathrm{Ma}$ from dredged volcanic rocks (Ozima et al., 1977) would imply a middle Albian age. However, dredge samples from nearly Taikuyo Daini Seamount yielded a plateau age of $118.4 \pm 1.8 \mathrm{Ma}$, indicating an earliest Aptian to latest Barremian age for the volcanic edifice (Pringle and Duncan, this volume).

In order to determine the possibility of a correlation of the upwardshallowing cycles in Hole 879A to the Aptian-Albian sequence stratigraphy from French outcrops, we will make three assumptions: (1) the formation of the carbonate platform on Takuyo-Daisan was not interrupted by long-term hiatuses in thermal subsidence of the seamount or by extended lowstands of sea level for more than 1 m.y., and, therefore, all sea-level variations with periods longer than $1 \mathrm{~m} . \mathrm{y}$. are recorded in the sediment successions; (2) the carbonate platform was initiated in the early-late Aptian, as indicated by the nannofossil and planktonic foraminifer assemblages; and (3) the total duration represented by the 170 -m-thick carbonate platform was a maximum of $6 \mathrm{~m}$.y. The constraint on the duration of the carbonate platform was derived assuming a typical subsidence rate of 25 to $30 \mathrm{~m} / \mathrm{m}$.y. for a seamount about 5 m.y. after it formed on older oceanic lithosphere (e.g., Detrick and Crough, 1978; Stein and Stein, 1993; Larson, this volume). A similar rate of subsidence is derived if one assumes that the typical 3-m-thick parasequence represents a 100,000 yr Milankovitch oceanic cooling cycle. The effect of these simplifying, and possibly erroneous, assumptions is to limit the age span of the carbonate platform in Hole 879A to late Aptian through the early Albian.

The late Aptian portion of the sequence stratigraphy scale of Haq et al. (1988) consists of a single highstand-lowstand-highstand cycle (uppermost Sequence LZB-4.1, and the relatively long-duration lowstand and shorter duration early highstand of Sequence LZB-4.2), with a short-duration lowstand (base of Sequence LZA-1.1) assigned to the basal Albian. The next highstand-lowstand pair has a relatively long duration (upper Sequence LZA-1.1 and lower Sequence LZA1.2; Fig. 9).
If one assumes a one-to-one correspondence of the depositional systems tracts of Hole $879 \mathrm{~A}$ with the rises and falls of eustatic sea level as interpreted by Haq et al. (1988), then the biostratigraphic ages imply a unique set of sequence assignments (Table 2; Fig. 9). The sequence boundaries were named by Haq et al. (1988) according to their time scale; however, because of the variability in published Aptian-Albian time scales, these "ages" mainly provide a nomenclature system and an indication of relative durations.

1. The initial submergence of the weathered volcanic edifice in Hole $879 \mathrm{~A}$ is assigned to the late highstand of upper Sequence LZB4.1 , or approximately at $110.5 \mathrm{Ma}$. The cyclic shallow-lagoon deposits of Subunits ID to IC ( $39 \mathrm{~m}$ thick) are assigned to the late highstand and lowstand systems tracts of upper Sequence LZB-4.1 to lower Sequence LZB-4.2, although a "lowstand" systems tract did not form on this subsiding platform. The "109.5" sequence boundary is arbitrarily placed in the middle of Subunit IC where the upward-shoaling cycles have emergent upper surfaces. The rapid deepening at the top of Subunit IC is assigned to the transgression in Sequence LZB-4.2, or approximately $108.5 \mathrm{Ma}$. Therefore, the relative duration of Subunits ID and IC is approximately 2 m.y. on the Haq et al. (1988) time scale, implying an average subsidence rate of $20 \mathrm{~m} / \mathrm{m}$.y.. This duration is longer than a 1.2-m.y. estimate obtained by assuming that each of the 12 parasequence upward-shoaling cycles in this interval represents a 100,000 yr Milankovitch cycle. However, if one assumes that the initial submergence was within the latest stage of the highstand systems tract (or approximately $110 \mathrm{Ma}$ ), then the duration of $1.5 \mathrm{~m} . \mathrm{y}$. for Subunits ID and IC would be more consistent with the number of parasequences and with the $30 \mathrm{~m} / \mathrm{m}$.y. subsidence rate computed for the overlying subunits.

2. The second depositional unit of the quiet lagoon to cyclic shallow-lagoon facies of Subunits IB-1 to IB-4 (38 m) is assigned to the transgressive (108.5 Ma) and highstand portions of Sequence LZB-4.1 and lowstand portion of Sequence LZA-1.1 (Fig. 9). The "108 Ma" maximum flooding surface would occur within the deep lagoon deposits, presumably in the lower portion of Subunit IB-3 at about $115 \mathrm{mbsf}$, and the "107.5 Ma" sequence boundary may be at the base of Subunit IB-4 at 102 mbsf. The cycle ends with a deepening at the top of Subunit IB-4, which is assigned to the transgression in Sequence LZA-1.1 (approximately 107.2 Ma). The duration of this cycle is also approximately 1.3 m.y. on the Haq et al. (1988) time scale, which implies an average subsidence rate of $29 \mathrm{~m} / \mathrm{m}$.y (Table 2). The transgressive to early-highstand portion of this cycle on the Haq et al. (1988) scale is twice as long as the following short-duration late-highstand to lowstand episode. These proportions are consistent with the deep-lagoon facies of this second depositional unit being approximately twice the thickness of the cyclic shallow-lagoon facies.

3. The third depositional unit, of possible early Albian age, is the transgressive and highstand systems tracts of Subunit IB-5 through the "lowstand" deposits of Subunit IA-2 (84 m). This unit is assigned to the upper portion of Sequence UZA-1.1 and the lower portion of UZA-1.2. The "107" maximum flooding surface may be equivalent to the top of Subunit IB-5 ( 83 mbsf), and the " 106 " sequence boundary is assigned to the rapid onset of oncolite-rich Subunit IA-1 (39 mbsf). The initial phases of the transgression that terminates Subunit IA-2 (4 mbsf) is at approximately 104.5 Ma on the Haq et al. (1988) time scale. The implied duration of this unit is approximately 2.5 to 3 m.y. on the Haq et al. (1988) time scale, which is consistent with its thickness being approximately twice that of the lower units. The associated subsidence rate is $31 \mathrm{~m} / \mathrm{m}$.y., which is the same as for the previous cycle (Table 2).

The total duration of these three depositional units on the Haq et al. (1988) time scale is approximately $5.7 \mathrm{~m} . \mathrm{y}$. (approximately 110.2 $\mathrm{Ma}$ to $104.5 \mathrm{Ma}$ ). In comparison, if one assumes that a 3-m upwardshoaling parasequence is equivalent to a 100-k.y. Milankovitch cycle, 
Table 2. Sequence stratigraphy interpretation of carbonate platform succession in Hole 879A and possible correlation to late Aptian and early Albian eustatic sea-level rises and associated ages compiled by Haq et al. (1988).

\begin{tabular}{|c|c|c|c|c|c|c|}
\hline $\begin{array}{c}\text { Major } \\
\text { deepening } \\
\text { (mbsf) }\end{array}$ & Subunit assignment and age & $\begin{array}{c}\text { Thickness } \\
\text { (m) }\end{array}$ & $\begin{array}{c}\text { Sea-level rise } \\
\text { (Haq et al., } \\
1988)\end{array}$ & $\begin{array}{c}\text { Associated } \\
\text { age estimate } \\
\text { (Ma) }\end{array}$ & $\begin{array}{l}\text { Implied } \\
\text { age span } \\
\text { (m.y.) }\end{array}$ & $\begin{array}{c}\text { Mean } \\
\text { subsidence rate } \\
(\mathrm{m} / \mathrm{m} . \mathrm{y} .)\end{array}$ \\
\hline & Subunits IA-3 and IA-4 ( $4.0 \mathrm{~m}$ thickness) are part of terminal transgressive drowning & & & & & \\
\hline 4.0 & $\begin{array}{l}\text { Base of Subunit IA-3; middle Albian? } \\
\text { Subunits IB-5 to IA-2 (possible sequence boundary at } 39 \text { mbsf, base of Subunit IA-1) }\end{array}$ & 84.0 & in LZA 1.2 & 104.5 & 2.7 & 31 \\
\hline 88.0 & $\begin{array}{l}\text { Base of Subunit IB-5; early Albian; relatively minor deepening episode } \\
\text { Subunits IB-1 to IB-4 (possible sequence boundary at } 102 \text { mbsf, base of Subunit IB-4) }\end{array}$ & 37.6 & in L.Z.A 1.1 & 107.2 & 1.3 & 29 \\
\hline 125.6 & $\begin{array}{l}\text { Base of Subunit IB-1; late Paleocene } \\
\text { Subunits ID and IC (possible sequence boundary at } 142 \text { mbsf, top of parasequence IC-3) }\end{array}$ & 38.8 & in LZB 4.2 & 108.5 & $2.0-1.5$ & $20-26$ \\
\hline \multirow[t]{2}{*}{164.4} & Base of carbonate platform; interpreted as edifice submergence within late highstand stage & & in LZB 4.1 & $110.0-110.5$ & & \\
\hline & Entire carbonate platform & 164.4 & & & 5.7 & 29 \\
\hline
\end{tabular}

Note: These major sequences contain higher order sequences and parasequences. The numbered Aptian-Albian sequences occur in the "Lower Zuni B" (UZB) and "Upper Zuni A" (UZA) second-order super-sequence set of Haq et al. (1988), and the relative ages of the onset of rapid sea-level rise within each sequence is estimated from the shape of their eustatic curve between the bounding sequence boundaries. Their time scale assigns $113 \mathrm{Ma}$ to the base of the Aptian, $108 \mathrm{Ma}$ to the Aptian/Albian boundary, and $96 \mathrm{Ma}$ to the top of the Albian. The mean subsidence rates assume that each major deepening event is initiated from the same shallow-water depth of deposition and that there is not a significant long-term rise or fall of eustatic sea level superimposed on the sequence set.

then the $164 \mathrm{~m}$ of carbonate platform sediments encompass approximately 5.5 m.y.

Therefore, under these simplifying age assumptions, the stratigraphy of Hole $879 \mathrm{~A}$ is generally remarkably consistent with the postulated ages and relative durations of the eustatic sea-level curve of Haq et al. (1988), which in turn summarizes the major facies patterns observed in the Aptian-Albian formations of Northwest Europe. Of course, the apparent agreements of these relative durations between France and the Pacific may be largely fortuitous, especially considering the major assumption that there are no major hiatuses in accumulation of the carbonate platform. However, the same succession of late Aptian and Albian sequences are recorded in the Basco-Cantabrian basin of northern Spain with comparable estimates of relative magnitude (Gräfe, 1994).

The "104.5 Ma" transgression of Sequence UZA-1.2 is shown with a smaller magnitude and slower rate of rise than the preceding transgressive events in the eustatic sea-level curve of Haq et al. (1988; Fig. 9). The tentative correlation of this transgression to the final drowning episode of the Takuyo-Daisan carbonate platform would present a dilemma. Why would a drowning be associated with this event but not for the previous major transgressions? In contrast, the basin sea-level curve derived from northern Spain indicates that the "104.5 Ma" transgression has the greatest magnitude of any event during the Albian prior to a similar magnitude event in the latest Albian. The latest Albian event has been correlated to the drowning of MIT Guyot and other carbonate platforms (e.g., Grötsch and Flügel, 1992; Grötsch et al., 1993); therefore, it seems acceptable that a transgressive rise of nearly equivalent magnitude during the early Albian played a key role in the final demise of the Takuyo-Daisan Guyot platform.

\section{Drowning of Takuyo-Daisan Guyot}

There are at least two possible final-stage scenarios envisioned for the termination of the carbonate platform of Takuyo-Daisan Guyot (Subunit IA-1):

1. The final stages of sedimentation at this site were later removed by erosion associated with emergence and/or submarine scouring and dissolution. In this case, the final stages leading to drowning of the guyot are not preserved in Hole 879A.

2. The uppermost 4-m-thick Subunit IA-1 records deposition during the initial stages of drowning. If the $30 \mathrm{~cm}$ of recovery in Core $144-879 \mathrm{~A}-1 \mathrm{R}$ is a representative sample, then the uppermost facies are concentrations of gastropod, rudist, rhodolith, and other shell fragments from current and/or wave reworking of "lagoonal" sediment. These were probably deposited as sand shoals. These deposits are similar to the storm-redeposited debris piles of Subunit IA-2, which have evidence of brief emergent episodes, and do not appear to record a final "drowning" assemblage into deep water. However, these upper sands do not display evidence of emergence, therefore may be partially a produce of reworking by oceanic currents sweeping across the platform. Direct evidence of extended periods of exposure and karst solution/cementation before drowning is lacking in the cores and logs.

The carbonate platform of Takuyo-Daisan Guyot experienced at least two major transgressive deepenings, but without suffering a terminal cessation of carbonate deposition. A constant rate of subsidence, coupled with the tentative correlations to Aptian-Albian sequences on European margins would imply that the final drowning coincided with a major transgression in the early Aptian Sequence UZA-1.2 in the Haq et al. (1988) compilation. As noted previously, there are conflicting estimates of the magnitude of this early Albian transgressive deepening (Gräfe, 1994), but it may have been the highest amplitude event between the earliest Aptian and latest Albian.

At Limalok Guyot (Site 871), the termination of the early Tertiary platform may have been associated with proximity to the nutrient-rich, near-equatorial paleolatitudes (Ogg et al., this volume). However, in Hole $879 \mathrm{~A}$, neither the core recovery nor the natural-gamma-ray log of uranium concentration displays any indications of anomalous abundance of algae. "Nutrient poisoning" of a reef is when algal growth accelerated by increased nutrient supply begins to dominate the reef ecosystem. Nutrient excesses may have been a factor in the termination of some carbonate platforms (e.g., Schlager, 1989; Vogt, 1989; Wood, 1993). However, near-equatorial reef systems thrive in the Maldives and Seychelles, and this "nutrient poisoning" phenomenon can not be documented in Hole 879. Indeed, the main enrichment in algal-cyanobacterial features is in the lower portion of the carbonate platform.

The closest analogy may be the drowning of the carbonate platform of Wodejebato Guyot (Site 874), where a lagoonal barrier-shoal complex was also built by storm-redeposition during an extended sea-level stillstand (Camoin et al., this volume). During the next Maastrichtian transgression, the seaward zone of active carbonate production backstepped onto this shallow-shoal complex. As sea level continued to rise, the sediment from this perched carbonate-sediment factory was shed into the deeper depths of both the lagoon side (perhaps equivalent to the storm-redeposited coral-rich floatstone of Subunit IA-2 at this Site) and seaward side of this rim, rather than forming another higher terrace on which the carbonate system could continue to back-step. The eventual result was the drowning of the carbonate-sediment factory as sea level continued to rise, because the continual removal of its sediment precluded it from keeping pace by building upward. Under 
this Wodejebato model, the termination of Takuyo-Daisan Guyot was linked directly to the earlier formation of an elevated rim of coarse sediment shoals (Subunit IA-2) during an interval of extended sealevel lowstand. Other factors that probably entered may have been deterioration of ideal growth environments for calcareous organisms because of the approach to the paleo-equator (i.e., warmer temperatures, increased nutrients for algae, episodes of rainfall-dilution of salinity, and increased frequency and amplitude of El Niño effects) and the general global warming during the late Aptian-Albian. The final drowning was probably a deadly combination of a major sea-level rise following an extended interval of stillstand, the inability of the main carbonate-sediment factory to keep pace with a rapid and continuous rise in sea levels, and unfavorable environmental conditions in nearequatorial latitudes during the Aptian-Albian.

\section{ACKNOWLEDGMENTS}

This research was sponsored by the Ocean Drilling Program and USSAC. Many of our interpretations of the depositional history are based upon the observations and presentations by our shipboard colleagues. Kai-Uwe Gräfe and Jürgen Grötsch provided preprints of their publications on sequences and drowning unconformities in Aptian-Albian carbonate platforms. Gabi Ogg drafted key figures and aided production of the manuscript versions. Valuable reviews and critiques were provided by James F. Bristow, Elizabeth Lewis Pratson, and Janet Haggerty.

\section{REFERENCES}

Asquith, G.D., 1979. Subsurface Carbonate Depositional Models: A Concise Review: Tulsa, OK (Petroleum Publ. Co.).

Bourke, L., Delfiner, P., Fett, T., Grace, M., Luthi, S., Serra, O., and Standen, E., 1989. Using Formation MicroScanner images. Tech. Rev., 37:16-40.

Cooper, P., Flood, P., and Arnaud, H., in press. Detailed lithologic control in carbonates from integration of core, FMS, and conventional well logs, Sites 865 and 866. In Winterer, E.L., Sager, W., Firth, J.V., and Sinton, J.M. (Eds.), Proc. ODP, Sci. Results, 143: College Station, TX (Ocean Drilling Program).

Detrick, R.S., and Crough, S.T., 1978. Island subsidence, hot spots, and lithospheric thinning. J. Geophys. Res., 83:1236-1244.

Dorfman, M.G., Newey, J.-J., and Coates, G.R., 1990. New techniques in lithofacies determination and permeability prediction in carbonates using well logs. In Hurst, A., Lovell, M.A., and Morton, A.C. (Eds.), Geological Applications of Wireline Logs. Geol. Soc. Spec. Publ. London, 48:113120.

Drummond, C.N., and Wilkinson, B.H., 1993a. Aperiodic accumulation of cyclic peritidal carbonate. Geology, 21:1023-1026.

1993b. On the use of cycle thickness diagrams as records of long-term sealevel change during accumulation of carbonate sequences. $J$. Geol., 101:687-702.

Ekstrom, M.P., Dahan, C.A., Chen, M.-Y., Lloyd, P.M., and Rossi, D.J., 1986. Formation imaging with microelectrical scanning arrays. Trans. SPWLA 27th Annu. Logging Symp., Pap. BB.

Goldhammer, R.K., Dunn, P.A., and Hardie, L.A., 1990. Depositional cycles, composite sea-level changes, cycle stacking patterns, and the hierarchy of stratigraphic forcing: examples from Alpine Triassic platform carbonates. Geol. Soc. Am. Bull., 102:535-562.

Goldhammer, R.K., Lehmann, P.J., and Dunn, P.A., 1993. The origin of high-frequency platform carbonate cycles and third-order sequences (Lower Ordovician El Paso Gp, west Texas): constraints from outcrop data and stratigraphic modeling. J. Sediment. Petrol., 63:318-359.

Gräfe, K.-U., 1994. Sequence stratigraphy in the Cretaceous and Paleogene (Aptian to Eocene) of the Basco-Cantabrian Basin (N. Spain). Tub. Geowiss. Arbeiten, Reihe A, 18.

\footnotetext{
- Abbreviations for names of organizations and publications in ODP reference lists follow the style given in Chemical Abstracts Service Source Index (published by American Chemical Society).
}

Gräfe, K.-U., and Wiedmann, J., 1993. Sequence stratigraphy in the Upper Cretaceous of the Basco-Cantabrian Basin (northern Spain). Geol. Rundsch., 82:327-361.

Grötsch, J., 1994. Guilds, cycles and episodic vertical aggradation of a reef (late Barremian to early Aptian, Dinaric carbonate platform, Slovenia). Spec. Publ. Int. Assoc. Sedimentol., 19:227-242.

Grötsch, J., and Flügel, E., 1992. Facies of sunken Early Cretaceous atoll reefs and their capping late Albian drowning succession (northwestern Pacific). Facies, 27:153-174.

Grötsch, J., Schroeder, R., Noé, S., and Flügel, F., 1993. Carbonate platforms as recorders of high-amplitude eustatic sea-level fluctuations: the late Albian appenninica event. Basin Res., 5:197-212.

Haq, B.U., Hardenbol, J., and Vail, P.R., 1988. Mesozoic and Cenozoic chronostratigraphy and cycles of sea-level change. In Wilgus, C.K., Hastings, B.S., Kendall, C.G.St.C., Posamentier, H.W., Ross, C.A., and Van Wagoner, J.C. (Eds.), Sea-Level Changes-An Integrated Approach. Spec. Publ.-Soc. Econ. Paleontol. Mineral., 42:72-108.

Hay, W.W., and Leslie, M.A., 1990. Could possible changes in global groundwater reservoir cause eustatic sea level fluctuations? In Revelle, R. (Ed.), Sea Level Change: Washington, D.C. (National Research Council, Studies in Geophysics/National Academy Press), 161-170.

Jones, B., and Desrochers, A., 1992. Shallow platform carbonates. In Walker. R.G., and James, N.P. (Eds.), Facies Models: Response to Sea Level Change. Geol. Assoc. Can., 277-301.

Molinie, A.J., and Ogg, J.G., 1992a. Milankovitch cycles in Upper Jurassic and Lower Cretaceous radiolarites of the equatorial Pacific: spectral analysis and sedimentation rate curves. In Larson, R.L., Lancelot, Y., et al., Proc. ODP, Sci. Results, 129: College Station, TX (Ocean Drilling Program), 529-547.

, 1992b. Formation microscanner imagery of Lower Cretaceous and Jurassic sediments from the western Pacific (Site 801). In Larson, R.L., Lancelot, Y., et al., Proc. ODP, Sci. Results, 129: College Station, TX (Ocean Drilling Program), 671-691.

Ogg, J.G., Karl, S.M., and Behl, R.J., 1992. Jurassic through Early Cretaceous sedimentation history of the central equatorial Pacific and of Sites 800 and 801. In Larson, R.L., Lancelot, Y., et al., Proc. ODP, Sci. Results: College Station, TX (Ocean Drilling Program), 571-613,

Osleger, D., 1991. Subtidal carbonate cycles: implications for allocyclic vs. autocyclic controls. Geology, 19:917-920.

Osleger, D., and Read, J.F., 1993. Comparative analysis of methods used to define eustatic variation in outcrop: Late Cambrian interbasinal sequence development. Am. J. Sci., 293:157-216.

Ozima, M., Honda, M., and Saito, K., $1977 .{ }^{40} \mathrm{Ar} /{ }^{39} \mathrm{Ar}$ ages of guyots in the western Pacific and discussion of their evolution. Geophys. J. R. Astron. Soc., 51:475-485.

Pezard, P.A., and Luthi, S., 1988. Borehole electrical images in the basement of the Cajon Pass Scientific drillhole, California: fracture identification and tectonic implications. Geophys. Res. Lett., 15:1017-1020.

Plint, A.G., Eyles, N., Eyles, C., and Walker, R.G., 1992. Control of sea level change. In Walker, R.G., and James, N.P. (Eds.), Facies Models: Response to Sea Level Change: St. John's, Newfoundland (Geol. Assoc. Can.), $15-25$.

Pratt, B.R., James, N.P., and Cowan, C.A., 1992. Peritidal carbonates. In Walker, R.G., and James, N.P. (Eds.), Facies Models: Response to Sea Level Change. Geol. Assoc. Can., 303-322.

Premoli Silva, I., Haggerty, J., Rack, F., et al., 1993. Proc. ODP, Init. Repts., 144: College Station, TX (Ocean Drilling Program).

Revelle, R. (Ed.), 1990. Sea Level Change: Washington, D.C. (National Research Council, Studies in Geophysics/National Academy Press).

Schlager, W., 1989. Drowning unconformities on carbonate platforms. In Wilgus, C.K., Hastings, B.S., Kendall, C.S., Posamentier, H.W., Ross, C.A., and van Wagoner, J.C. (Eds.), Sea Level Changes-An Integrated Approach. Spec. Publ.-Soc. Econ. Paleontol. Mineral., 42:15-25.

Serra, O., 1985. Shallow-water carbonate environment. In Sedimentary Environments from Wireline Logs (Sect. 5.8): Houston (Schlumberger Educational Services), 143-154.

Shipboard Scientific Party, 1993. Site 879. In Premoli Silva, I., Haggerty, J., Rack, F., et al., Proc. ODP, Init. Repts., 144: College Station, TX (Ocean Drilling Program), 413-441.

Stein, C.A., and Stein, S., 1993. Constraints on Pacific midplate swells from global depth-age and heat flow-age models. In Pringle, M.S., Sager, W.W. Sliter, W.V., and Stein, S. (Eds.), The Mesozoic Pacific: Geology, Tectonics, and Volcanism. Am. Geophys. Union, Geophys. Monogr., 77:53-76. 
Tucker, M.E., and Wright, P.V., 1990. Carbonate Sedimentology: Oxford (Blackwell Sci. Publ.).

van Waasbergen, R.J., and Winterer, E.L., 1993. Summit geomorphology of Western Pacific guyots. In Pringle, M.S., Sager, W.W., Sliter, W.V., and Stein, S. (Eds.), The Mesozoic Pacific: Geology, Tectonics, and Volcanism. Geophys. Monogr., Am. Geophys. Union, 77:335-366.

Van Wagoner, J.C., Mitchum, R.M., Campion, K.M., and Rahmanian, V.D., 1990. Siliciclastic Sequence Stratigraphy in Well Logs, Cores, and Outcrops: Concepts for High-Resolution Correlation of Time and Facies. AAPG Methods Explor. Ser., 7.

Vogt, P.R., 1989. Volcanogenic upwelling of anoxic, nutrient-rich water: a possible factor in carbonate-bank/reef demise and benthic faunal extinctions? Geol. Soc. Am. Bull., 101:1225-1245.

Wilson, J.L., 1975. Carbonate Facies in Geologic History: Berlin (SpringerVerlag).

Wood, R., 1993. Nutrients, predation and the history of reef-building. Palaios, $8: 526-543$

\section{Date of initial receipt: 15 March 1994 Date of acceptance: 15 September 1994 Ms 144SR-043}

\section{APPENDIX}

\section{Description and Interpretation of Facies Subunits}

The following summary of the carbonate facies integrates the independent observations from the cored sediments (typically $10-50 \mathrm{~cm}$ of recovery from each $10-\mathrm{m}$ cored interval), the quantitative resistivity measurements, the natural-gamma-ray intensities and associated uranium/thorium/potassium abundances, the detailed FMS "textures" and vertical successions, and neutron porosity logs. Division of the lithologic succession into subunits is initially based upon the facies and nomenclature of shipboard-defined lithologic units. At Site 879, the carbonate platform succession was denoted as lithologic Unit I with lettered subunits. The carbonate platform overlies a clay-rich weathering horizon (lithologic Unit II) developed on the volcanic edifice (lithologic Unit III). Additional subdivisions are defined according to coherent log-facies packets or individually by recognized parasequences (Fig. 1). These subunits simplify later discussions of sedimentary history interpretation.

Relative FMS resistivity (darkness on gray-scale imagery) is expressed in a shorthand of "low" $(<2 \Omega-\mathrm{m})$, "medium" $(2-5 \Omega-\mathrm{m})$, and "high" $(>5 \Omega-\mathrm{m})$ resistivity, after calibrating with the corresponding resistivity log values. Relative resistivity of features produced in the dynamic-processed enhanced FMS imagery are denoted as "higher" or "lower" resistivity, and do not imply fixed resistivity ranges. In the accompanying log-stratigraphy columns, the resistivity values from the shallow-focused resistivity tool (SFLU instrument) are plotted after depth-shifting to FMS depths. Some features on this resistivity $\log$ (resolution of $1 \mathrm{~m}$ ) have been adjusted by increasing or decreasing the sharpness and amplitude of peaks to agree with the high-resolution resistivity records of the FMS imagery (resolution of $2.5 \mathrm{~mm}$ ).

Depths, except for quoted cored intervals, are according the FMS "reference" log, as processed by LDEO-BRG.

\section{Lithologic Unit III: Volcanic Breccia and Basalt Flows ( 190.0 mbsf to base of hole at $226.5 \mathrm{mbsf}$; $>36.5 \mathrm{~m}$ thickness)}

Core 144-879A-24R (217.0-226.5 mbsf; $0.9 \mathrm{~m}$ recovery): Volcanic breccia and basalt.

Core 144-879A-23R (207.6-217.0 mbsf; $5.8 \mathrm{~m}$ recovery): Basalt and volcanic breccia.

Core 144-879A-22R (198.1-207.6 mbsf; $9.3 \mathrm{~m}$ recovery): Basalt and volcanic breccia, with one horizon of well-sorted, reworked-volcanic sandstone.

Core 144-879A-2IR (188.7-198.1 mbsf; $2.4 \mathrm{~m}$ recovery): Lower $1.5 \mathrm{~m}$ of core is basalt and volcanic breccia.

\section{Summary and Interpretation of Logging Facies}

Resistivity $\log$ and FMS imagery only extend to $213.9 \mathrm{mbsf}$. The logged interval of $24 \mathrm{~m}$ within lithologic Unit III displays four, evenly spaced, sharp-bounded, meter-thick layers of high resistivity $(10-40 \Omega$-m) interbedded with a facies of low to medium resistivity (5-10 $\Omega$-m) (Fig. 1, back pocket). This succession is interpreted to be four main basalt flows interbedded with volcanic breccia or relatively altered basalt. The top of lithologic Unit III was placed at $190.0 \mathrm{mbsf}$ at the initiation of an extended interval of very low resistivity associated with the claystone facies of lithologic Unit II.

The four main high-resistivity layers are approximately $1 \mathrm{~m}$ in thickness (192.0-192.8, 200.8-201.8, 206.2-207.2, and 212.4 to below $213.9 \mathrm{mbsf}$ ). In the FMS imagery, the basalt layers display either sharp contacts or rapid transitions over a few tens of centimeters to the interbedded low-resistivity facies (Fig. 3). Some of these basalt layers recovered during coring were interpreted to be formed by intrusion of basaltic lava into soft, wet volcanic breccia (Shipboard Scientific Party, 1993). The uppermost layer has a relatively lower resistivity with a transitional upper surface into the thick claystone soil-horizon facies of lithologic Unit II; this uppermost basalt layer is interpreted to be more altered by weathering.

The intervening volcanic breccia-dominated intervals are $\sim 5 \mathrm{~m}$ thick. The FMS imagery of these intervals is characterized by (1) numerous diagonal low-resistivity veins of approximately $1 \mathrm{~cm}$ thickness, which may correspond to the abundant calcite veins within the recovered facies; and (2) a mottled or patchy pattern of higher and lower relative resistivity at the 5-20-cm scale, which is interpreted to represent irregular alteration to clay minerals (Fig. 3). The mottles of relatively higher resistivity probably represent localized patches of less weathered or altered volcanic breccia. These intervals contain several 1-m-thick peaks of intermediate resistivity. The complete recovery of Core 144-879A-22R indicates that some of these intermediate peaks may be basalt having a greater degree of alteration.

Lithologic Unit II: Claystone Formed from Weathered Volcanic Breccia (164.4-190.0 mbsf; $25.6 \mathrm{~m}$ thickness)

Core 144-879A-21R (188.7-198.1 mbsf: $0.4 \mathrm{~m}$ recovery): Upper $60 \mathrm{~cm}$ of core is conglomerate of volcanics, altered to dark brown claystone; overlying basalt.

Core 144-879A-20R(179.4-188.7 mbsf; 8.1 m recovery): Claystone, dark red to reddish black, formed by alteration of volcanic breccia.

Core 144-879A-19R (169.7-179.4 mbsf; $4.8 \mathrm{~m}$ recovery): Claystone interbedded with altered volcanic breccia; reddish brown.

Core 144-879A-18R (160.1-169.7 mbsf; $0.5 \mathrm{~m}$ recovery): Lower $20 \mathrm{~cm}$ of core is clay-rich, bioturbated sandstone of volcanic, carbonate, and coalrich grains.

\section{Summary and Interpretation of Logging Facies}

This interval is characterized by sustained very low resistivity $(2-3 \Omega-m)$ corresponding to the pervasive weathering alteration of the former volcanic breccia to claystone (Fig. 1). The FMS imagery displays a background mottling at a $5-\mathrm{cm}$ scale with patches of relatively higher resistivity material and a ubiquitous web of extremely low-resistivity veins. This FMS texture corresponds to the irregular weathering of the volcanic breccia and associated networks of clay enrichment.

The top of lithologic Unit II was placed at the sharp base of a mediumresistivity, low-gamma layer, which is interpreted to be the lowest wellcemented, carbonate-rich bed. The uppermost $2 \mathrm{~m}$ of lithologic Unit II has a slightly higher resistivity and is interpreted to be the organic-rich sandstone recovered in the basal pieces of Core 144-879A-18R. There seems to be a sharp contact at $166.8 \mathrm{mbsf}$ between the claystone of weathered volcanic breccia and the sandstone of mixed volcanic and carbonate grains. This uppermost zone probably represents the initial flooding of the volcanic edifice capped by clay-rich soil.

Natural-gamma-ray intensity displays a progressive upward decrease until a peak in the uppermost $2 \mathrm{~m}$. The lower portion of this natural-gamma-ray trend is primarily caused by a reduction in potassium within the weathered volcanic breccia, which probably indicates an increasing degree of weathering of the volcanic breccia. The uppermost peak in natural-gamma-ray intensity corresponds to both an anomalous enrichment in uranium and a concentration of potassium and thorium. A redox concentration of uranium within the organicrich clayey sandstone layer, which is overlying the oxidized claystone and underlying a bioturbated packstone, is probably a major contribution to this peak.

Lithologic Subunit ID: Lagoonal Gastropod-bivalve Peloid Packstone Interbedded with Detrital Volcaniclastics (152.7-164.4 mbsf; 11.7 m thickness; late Aptian)

\section{Summary of Logging Facies}

This subunit is characterized by a series of peaks in both resistivity and natural-gamma-ray intensity (Fig. 1). The low-resistivity layers, typically 
$20-70 \mathrm{~cm}$ thick, correspond to high natural gamma-ray intensities produced by simultaneous concentrations of potassium, thorium and uranium. The peaks in resistivity correspond to low values in natural-gamma-ray intensity. The higher resistivity facies is mottled by centimeter-scale patches of lower resistivity and distinct "holes" in the FMS imagery (Figs. 3 and 4). Where contacts between facies is sharp in FMS imagery, they display a preferential dip of about $10^{\circ}$ toward the west to northwest.

General Interpretation: This subunit is interpreted as a series of carbonate beds interbedded with clay or volcanic-grain rich horizons. Core recovery and FMS imagery indicate that the limestone facies is bioturbated with abundant molds of gastropods. The overall thickness of the carbonate-clay cycles is approximately 3 to $4 \mathrm{~m}$, which is comparable with upward-shallowing parasequences observed in the detailed FMS and geophysical logs within other Cretaceous carbonate platform successions drilled on Leg 144. The carbonate-clay pattern is consistent with a model of carbonate deposition during relatively rapid rises of sea level, followed by progradation of clastic influx from the exposed volcanic edifice during episodes of slowed sea-level rise. The rapid upward transitions in each cycle between clay-poor carbonate lagoonal sediments to clay-enriched intervals is equivalent to a small-scale "sequence boundary" of relatively rapid seaward shift of depositional environments.

The depositional environment is envisioned to be a quiet lagoon sandwiched between a barrier-shoal complex and a weathered volcanic island. The core recovery is a lagoonal facies dominated by bioturbated, gastropod-rich, skeletal peloid packstone with variable clay enrichment and with intervals containing abundant coated grains or intraclasts. The transition from the volcanic soil of lithologic Unit II to the interbedded volcanic detritus and lagoonal carbonates of lithologic Subunit ID followed by the quiet shallow lagoon facies of lithologic Subunit IC is consistent with a "Darwin" model of progressive subsidence and submergence of a reef-ringed volcanic edifice to create an atoll-like carbonate platform. The drowning of the edifice was accomplished in a series of pulses of relatively rapid sea-level rises separated by relative still-stands. Late Aptian nannofossils were found within this transgressive series (Shipboard Scientific Party, 1993). The average thickness of these cycles $(\sim 3 \mathrm{~m})$ is similar to the cycles characterizing the overlying lithologic Subunit IC.

Change in Subunit Definition: The shipboard distinction of separate lithologic Subunits ID and IE in this interval was based on the size-sorting of the terrigenous clastic influx from the emergent volcanic island into the carbonate platform facies: primarily of sand-sized grains (Subunit IE) or as clay (Subunit ID). However, this distinction was based on a sporadic $15 \%$ recovery. In the FMS and logging signatures, it appears that clay enrichment occurs in discrete layers throughout this $12-\mathrm{m}$ interval, so the shipboard distinction of two unique subunits appears to be an artifact of random recovery. Therefore, Subunit E was omitted. Subunit ID, characterized by the presence of significant terrigenous clastic influx episodes, was subdivided into four intervals (Logging Facies Subunits ID-1 through ID-4), equivalent to the four main upward-shallowing cycles. Each of these four intervals is capped by an enrichment in clay and/or sand. The core recovery associated with the original definition of a "clay-rich Subunit D" is probably equivalent to the new Logging Facies Subunit ID-4. The top of Subunit ID was assigned to the sharp top of the uppermost layer of significant low-resistivity and high-potassium-induced gamma-ray intensity.

\section{Logging Facies Subunit ID-1 (162.1-164.4 mbsf; 2.3 m thickness)}

Core 144-879A-18R (160.1-169.7 mbsf; $0.5 \mathrm{~m}$ recovery): Upper $30 \mathrm{~cm}$ of core is gastropod rudstone with matrix of bioturbated skeletal peloid packstone.

162.3-164.4 mbsf: Sharp base of medium- to high-resistivity peak, followed by a gradual decline in resistivity. The FMS imagery has a mottled texture on the $10-\mathrm{cm}$ scale, consistent with a packstone-wackestone lithology (Fig. 4). Some diffuse low-resistivity patches are subvertical and $5 \mathrm{~cm}$ long; these may be associated with bioturbation.

162.1-162.3 mbsf: This $20 \mathrm{~cm}$ layer has very low resistivity and a high peak of natural-gamma-ray intensity induced by a combination of potassium, thorium, and uranium. Sharp bounding contacts in the FMS imagery.

Interpretation: Transgressive surface at $164.4 \mathrm{mbsf}$ with onset of carbonate sedimentation. Basal few centimeters of lowest carbonate bed are well cemented, perhaps enhanced by redox processes at the contact to the underlying organic-bearing clastic sands. The uppermost $20 \mathrm{~cm}$ of the cycle is a progradation of clayey facies. The parasequence was terminated by another deepening pulse.

\section{Logging Facies Subunit ID-2 (157.7-162.1 mbsf; 4.4 m thickness)}

158.5-162.1 mbsf: Basal $15 \mathrm{~cm}$ bed of high resistivity is followed by a $50-\mathrm{cm}$ interval of low to medium resistivity, then a rapid upward increase in resistivity to a sharp-topped, 50-cm-thick high-resistivity bed at 160.1-160.6 mbsf containing 1-cm-scale "holes" (?gastropod molds). A second progression from medium-high to high resistivity is terminated at $159.0 \mathrm{mbsf}$ by a rapid transition to a lower resistivity facies. This transition is accompanied by an increase in natural-gamma-ray intensity caused by the presence of potassium, thorium, and uranium.

157.7-158.5 mbsf: The lower $50 \mathrm{~cm}$ displays contrasting low-and highresistivity mottles; the upper $30 \mathrm{~cm}$ is a layer of low resistivity (Fig. 5). Part of this apparent mottling of resistivity values may be caused by fluctuations in hole diameter and associated incomplete contact of the FMS pads.

Interpretation: Basal $15 \mathrm{~cm}$ is enhanced cementation of a transgressive carbonate at the contact to underlying clay-rich facies. The transgressive and highstand facies of bioturbated gastropod-rich peloid and coated-grain packstone-wackestone is followed by an increase in clay content, culminating in a clay-rich layer.

\section{Logging Facies Subunit ID-3 (155.5-157.7 mbsf; 2.2 m thickness)}

Core 144-879A-17R (150.4-160.1 mbsf; $2.2 \mathrm{~m}$ recovery): Lower $10 \mathrm{~cm}$ is intraclast and coated-grain rudstone. The majority of core is dark gray, clay-rich, bivalve-rich limestone to volcanic-carbonate sandstone. The upper $20 \mathrm{~cm}$ is peloid skeletal packstone, pale brown to reddish yellow, with oncoids.

156.4-157.7 mbsf: The lower $80 \mathrm{~cm}$ has medium resistivity with slightly higher resistivity at the base. This layer has a mottled appearance in the FMS imagery (Fig. 5), similar to underlying beds that are interpreted to be bioturbated packstone. A similar FMS texture is within the upper, 50-cm-thick. high-resistivity bed.

155.1-156.4 mbsf: A progressive shift to low resistivity corresponds to a peak in natural-gamma-ray intensity induced by combined thorium, potassium, and uranium concentrations. The uppermost $60 \mathrm{~cm}$ have low resistivity with some mottling with slightly higher resistivity.

Interpretation: This cycle is similar to the previous ones, but with a less pronounced basal cementation. Packstone representing the transgressive and highstand system tract of the parasequence is followed by a progressive increase in clay content. Bioturbation appears to be ubiquitous.

\section{Logging Facies Subunit ID-4 (152.7-155.5 mbsf; 2.8 m thickness)}

153.0-155.1 mbsf: This $1.9-\mathrm{m}$ interval is mainly medium resistivity with lower natural gamma-ray intensity and a mottled appearance in the FMS imagery (Fig. 6). The interval from 153.8 to $154.2 \mathrm{mbsf}$ is a 40 -cm-thick zone of relatively lower resistivity caused by an increased abundance of large low-resistivity mottles.

152.7-153.0 mbsf: This 30-cm layer of low resistivity (Fig. 6) coincides with a peak in natural-gamma-ray intensity induced by a combination of thorium, potassium, and uranium concentrations. There may be $\sim 20 \mathrm{~cm}$ offset between the FMS imagery and the natural-gamma-ray log in this interval, with the peaks in the natural-gamma-ray log being slightly higher than the equivalent levels in the FMS imagery.

Interpretation: This is the highest cycle containing significant clay enrichment. The $30-\mathrm{cm}$ clay-rich zone is tentatively correlated with the uppermost interval of significant clay-enriched, pyrite-rich skeletal packstone in Section $144-879 \mathrm{~A}-17 \mathrm{R}-1$ at $67-93 \mathrm{~cm}$. Above the top of the clay-rich interval at 152.7 mbsf, all peaks in natural-gamma-ray intensity are caused only by uranium, and the thorium and potassium associated with clay influx remain at background levels. Therefore, this level represents the final submergence of the portion of the volcanic edifice that influenced sedimentation at this site.

\section{Lithologic Subunit IC: Upward-shallowing Cycles in Lagoonal Gastropod-bivalve Peloid Wackestone-packstone with Oncolites (125.6-152.7 mbsf; $27.1 \mathrm{~m}$ thickness; late Aptian)}

\section{Summary of Logging Facies}

This interval comprises eight cycles with a steady periodicity of 3-4 m. Each cycle begins with a low-resistivity facies and is capped by a high-resistivity bed, often displaying a sharp upper contact to the next overlying low-resistivity 
facies (Fig. 7). These eight cycles were denoted Subunits IC-1 through IC-8. The high-resistivity beds in the upper portion of each cycle within the first six cycles are associated with peaks in natural-gamma-ray intensity caused by uranium concentrations. These uranium concentrations may be partially algalmicrobial induced. Oncoids were observed within the limited core recovery throughout this interval, and the abundance of 1- to 2-cm diameter, highresistivity spheres in FMS imagery is interpreted to be oncoid structures. Most of the FMS imagery displays a mottled texture at the 5- to 10-cm scale (Fig. 6), consistent with the wackestone-packstone facies in the core recovery.

General Interpretation: Each cycle is an upward-shallowing succession or parasequence, generally ending with a phase of oncolite enrichment. Each cycle is terminated by a relatively rapid deepening event that begins the next overlying cycle. Unlike algal-cyanobacterial-rich facies often associated with such parasequences at the other Leg 144 guyot sites, the FMS imagery did not indicate any significant algal mat or encrustation features. The rare presence of fenestral features in the limited core recovery suggests that some episodes included intertidal deposition. The resistivity amplitude of the cycles progressively increases upward through the suite, suggesting that a general shallowing trend is superimposed upon the higher frequency parasequences. In particular, cycles \#6 and \#8 (Subunits IC- 6 and IC- -8 ) have capping beds of extremely high resistivity, which may indicate enhanced cementation during episodes of emergence. This suite of cycles can be considered as a continuation of the cyclic sedimentation that characterized Subunit ID.

Change in Subunit Definition: The wackestone-packstone facies of Subunit IC contains dispersed grains within the carbonate facies. These grains were visually interpreted by the shipboard sedimentologists to be altered basalt (Shipboard Scientific Party, 1993). The contact between lithologic "Subunit IC" and the similar carbonate facies of the lower portion of "Subunit IB" was defined by the Shipboard Scientific Party (1993) as the apparent disappearance of these scattered basaltic grains between Cores 144-879A-16R and -15R at $140.8 \mathrm{mbsf}$. The lowermost $29 \mathrm{~m}$ of this shipboard-defined Subunit IB has only $0.7 \mathrm{~m}$ total recovery; therefore, the shipboard distinction of a significant subunit contact was based only on rare and random sampling of the actual lithologic succession in the borehole. The low abundance of these distributed volcanic grains does not contribute a thorium and potassium signal to the observed natural-gamma-ray intensity, which is dominated by uranium in this interval, except perhaps in portions of parasequences IC-5 and IC- 6 (which are above the shipboard-assigned boundary). Therefore, it was not possible or considered important to use this minor volcanic-grain component as a definition of lithologic facies. In contrast, a more significant and sharply defined facies change is observed in the detailed logging record at $125.6 \mathrm{mbsf}$ (corresponding to the middle of Core 144-879A-14R). At this level, the underlying facies is characterized by pronounced cyclicity on the resistivity logs, whereas the overlying facies has subdued or insignificant cyclicity. Therefore, we have redefined the boundary between Subunits IC and IB at this major contrast.

\section{Logging Facies Subunit IC-1 (149.5-152.7 mbsf; 3.2 m thickness)}

151.8-152.7 mbsf: High-resistivity bed with a sharp basal contact to the clay-rich top of lithologic Subunit ID-4 and a mottled internal structure in the FMS imagery (Fig. 6).

149.5-151.8 mbsf: The basal few centimeters are of low resistivity. The remainder of this interval is of medium resistivity capped by a 80 -cm-thick, high-resistivity bed. The high-resistivity bed displays coalescing $3-\mathrm{cm}$-scale "spheres" of high resistivity in a medium-resistivity matrix and is associated with a peak in natural-gamma-ray intensity caused by a uranium concentration.

Interpretation: The majority of this interval is packstone, probably corresponding to the bioturbated skeletal packstone dominating the upper $80 \mathrm{~cm}$ of Core $144-879 \mathrm{~A}-17 \mathrm{R}$. The relatively low-resistivity layer at $151.8 \mathrm{mbsf}$ may correspond to the zone of slight clay enrichment at interval 144-879A-17R, $18-40 \mathrm{~cm}$. The capping medium- to high-resistivity bed appears to be rich in oncolites, and represents the shallowest phase of this parasequence.

\section{Logging Facies Subunit IC-2 (146.2-149.5 mbsf; 3.3 m thickness)}

Core 144-879A-16R (140.8-150.4 mbsf; $1.2 \mathrm{~m}$ recovery): Lower $40 \mathrm{~cm}$ is volcanic-grain-bearing skeletal wackestone with skeletal oncolite packstone. Upper $80 \mathrm{~cm}$ is skeletal to foraminifer wackestone, light gray, with oncolites and rare stromatoporoid and coral fragments.

146.2-149.5 mbsf: This interval has a progressive upward increase in resistivity, rising from a low-resistivity $40 \mathrm{~cm}$ layer up to a sharp-topped peak in resistivity that coincides with a major concentration of uranium and a peak in natural-gamma-ray intensity. This uranium concentration is the highest peak recorded within Hole 879A.

Interpretation: Foraminifer to skeletal wackestone, with a probable abundance of oncoids in an upper bed of packstone. The upward increase in resistivity (cementation) suggests a shallowing-upward trend.

\section{Logging Facies Subunit IC-3 (142.9-146.2 mbsf; 3.3 m thickness)}

142.9-146.2 mbsf: This cycle contains three alternations of relatively lower resistivity overlain by a higher resistivity facies. The FMS imagery indicates that high-resistivity, 1-cm-diameter "balls" comprise approximately $5 \%$ of some levels, but the overall texture is a diffuse mottling. The uppermost $50 \mathrm{~cm}$ displays a rapid upward increase to a sharp-topped "spike" of high resistivity (Fig. 7).

Interpretation: Wackestone-packstone with local oncolite enrichments. The upper surface on the well-cemented layer may be caused by emergence and corresponds to the interval of yellow-stained burrows and cavities with manganese dendrites at interval $144-879 \mathrm{~A}-16 \mathrm{R}, 68-94 \mathrm{~cm}$.

\section{Logging Facies Subunit IC-4 (140.0-142.9 mbsf; 2.9 m thickness)}

140.0-142.9 mbsf: The lower $1.5 \mathrm{~m}$ is a low-resistivity facies with scattered 1-cm-diameter "balls" of medium resistivity and sustained concentrations of uranium (Fig. 7). The upper $1.4 \mathrm{~m}$ displays a rapid upward increase in resistivity, culminating in a sharp upper contact to the low-resistivity base of the next cycle.

Interpretation: This cycle is an algal-cyanobacterial-rich succession (high uranium concentrations), which probably correlates with the oncoid-rich skeletal packstone in interval $144-879 \mathrm{~A}-16 \mathrm{R}, 3-68 \mathrm{~cm}$.

\section{Logging Facies Subunit IC-5 (136.0-140.0 mbsf; 4.0 m thickness)}

136.0-140.0 mbsf: This cycle exhibits a moderate uranium concentration and natural-gamma-ray intensity. This is the highest level of significant uranium concentration within Hole $879 \mathrm{~A}$. There is also a minor potassium and thorium component to the natural-gamma-ray spectra. The lower $2.3 \mathrm{~m}$ is low resistivity, followed by a rapid shift to a 1.7 -m-thick bed of high resistivity.

Interpretation: This cycle is the highest significant algal-microbial-rich succession with an associated uranium concentration and marks a change in the character of the cycles. The following three cycles display greater amplitudes of resistivity contrasts and pronounced cementation horizons (very high resistivity), which suggests shallowing-upward parasequences. Tentatively, this shift in cycle character is considered to represent a deposition during a relative fall of eustatic sea level (reduced accommodation space); therefore, a possible "sequence boundary" is assigned to Subunit IC-5.

\section{Logging Facies Subunit IC-6 (132.5-136.0 mbsf; 3.5 m thickness)}

Core 144-879A-15R (131.1-140.8 mbsf; 0.4 m recovery): Dense, bioturbated, peloid wackestone with gastropod molds, small benthic foraminifers. and fragments of bivalves and rudists; open burrows are sprinkled with manganese micronodules; fenestrae are common.

132.5-136.0 mbsf: This cycle has a rapid basal rise in resistivity, followed by a 1.9-m interval with low-resistivity patches within a high-resistivity matrix. This patchy interval is associated with a minor peak in natural-gamma-ray intensity, mainly induced by uranium but with minor peaks of thorium and potassium. The cycle culminates in a $90-\mathrm{cm}$ bed of very high resistivity, with a rapid uppermost transition to the next cycle. This upper well-cemented bed has small scattered low-resistivity "holes."

Interpretation: Cycle with an uppermost bed of dense peloid wackestonepackstone with molds of gastropods. The middle portion of this wackestonedominated cycle may have some minor clay or volcanic ash enrichment producing the observed minor abundances in thorium and potassium.

\section{Logging Facies Subunit IC-7 (128.4-132.5 mbsf; 4.1 m thickness)}

Core 144-879A-14R (121.5-131.1 mbsf; 0.3 m recovery): Mollusk-gastropod-peloid wackestone to rudstone; lower intervals also contain oncolites or fenestrae.

128.4-132.5 mbsf: The lower $90 \mathrm{~cm}$ has mottles of low- and high-resistivity in the FMS imagery, similar to bioturbated wackestone-packstone facies of 
other intervals. The next $1.1 \mathrm{~m}$ is a "void" in the logging, and probably represents a washed-out interval of poorly cemented material. The drilling records indicate no obvious drop through a cavern. The upper $2.4 \mathrm{~m}$ is a high-resistivity bed with a fine-mottling or moldic-porosity appearance in the FMS imagery. The cycle ends in a rapid transition to the low-resistivity basal facies of the next cycle.

Interpretation: Wackestone-packstone with an uppermost densely cemented bed containing gastropod molds. This cycle exhibits no apparent algal or oncoid component of sedimentation.

\section{Logging Facies Subunit IC-8 (125.6-128.4 mbsf; 2.8 m thickness)}

125.6-128.4 mbsf: Lower $1.5 \mathrm{~m}$ has a low- to medium-resistivity lithology with mottled texture in the FMS imagery. Upper $1.3 \mathrm{~m}$ is very high resistivity with a few low-resistivity 1-cm-diameter "voids." This single 1-m-thick bed required $36 \mathrm{~min}$ to core, equivalent to drilling basalt. The upper few centimeters display a rapid decrease to medium-resistivity.

Interpretation: This highest major cycle of gastropod-rich wackestone may have undergone an episode of emergence that produced the dense cementation and yellowish staining observed in the core pieces recovered.

\section{Lithologic Subunit IB: Foraminifer-gastropod-bivalve Packstone-wackestone (39.0-125.6 mbsf; $85.6 \mathrm{~m}$ thickness; late Aptian to Albian)}

\section{Summary of Logging Facies}

This lithologic subunit had only about $1 \%$ recovery during coring, and the greatly widened borehole resulted in both misleading resistivity values and the loss of detail during FMS logging. Therefore, the neutron porosity $\log$ (NPHI record) is used as a secondary monitor of facies changes. As indicated in Fig. 1, the neutron porosity $\log$ mirrors the resistivity $\log$ fluctuations within the upper portion of lithologic Subunit IC, but with significantly reduced resolution. The combination of logs enabled subdivision of Subunit IB into eight main logging facies; however, because of the lack of continuous high-resolution FMS imagery, the contacts of these subunits are only placed to the nearest meter. Subunits IB-1 and IB-2 are similar to the cycles of Subunit IC, but with a progressive reduction in resistivity. Subunit IB-3 has extremely low resistivity and high porosity. Subunit IB-4 has fluctuating or cyclic patterns of resistivity and porosity with approximately a 3-m periodicity. Some of these cycles are associated with peaks in natural-gamma-ray intensity. Subunit IB-5 is a transition to the low-resistivity facies of Subunits IB-6 through IB-8.

General Interpretation: Subunit IB represents two deep-lagoonal episodes (transgressive and early highstand facies), with an intervening shallowlagoon stage that has upward-shoaling cycles. Subunits IB-1 and IB-2 may represent upward-shallowing cycles superimposed on a progressive deepening trend, culminating in poorly cemented, lagoonal, foraminifer wackestone (Subunit IB-3). A shoaling led to the shallow-lagoon facies of Subunit IB-4, which is a shallow-lagoon facies of skeletal grainstone to algal-cyanobacterial and fenestral wackestone, with a succession of upward-shallowing cycles or parasequences similar to the upward-shallowing cycles of Subunit IC. Subunit IB-5 is another deepening event, followed by the deep-lagoonal facies of Subunits IB-6 through IB-8. The transition to overlying Subunit IA represents another onset of shallow lagoonal upward-shoaling cycles.

Change in Subunit Definition: Lithologic Subunit IB was defined by the shipboard sedimentologists as having a dominance of skeletal-foraminifer wackestone-packstone, in contrast to the abundance of coral-mollusk concentrations that defined lithologic Subunit IA. However, there was essentially no recovery of the important logging facies Subunits IB-4 through IB-7, which, as indicated by the few pieces in Cores 144-879A-10R and -11R, probably have similar concentrations of larger bioclasts. Indeed, Subunit IB appears to consist of three distinct sediment facies, that represent two deep-lagoon stages separated by an interval of shallow-lagoon to peritidal cycles. Therefore, we have revised the definition of the top of Subunit IB to be the base of the lowest bed of low porosity at 39 mbsf, which is considered to represent a rapid transition from a deep-water lagoon to another interval of shallow-lagoon parasequences. This new definition shifts the top of Subunit IB upward by about $5 \mathrm{~m}$.

\section{Logging Facies Subunit IB-1 (120.0-125.6 mbsf; 5.6 m thickness)}

120.0-125.6 mbsf: Layer of high resistivity at 123.7-124.5 mbsf, followed by a $2-m$ interval of low resistivity. Gradual increasing resistivity to a sharptopped, high-resistivity peak at 120.9-120.0 mbsf.
Interpretation: Upward-shallowing cycle, but relatively expanded in thickness and reduced in amplitude relative to the underlying upper cycles of Subunit IC-8. The lower portion of this cycle is probably uncemented foraminifer packstone. This unit indicates a deepening relative to the underlying emergent to well-cemented cyclic sediments. The cycle is terminated by another transgressive pulse.

\section{Logging Facies Subunit IB-2 (115-120 mbsf; 5 m thickness)}

115-120 mbsf: Low resistivity with a minor broad increase in resistivity and an associated reduction in porosity at $117.0-118.5 \mathrm{mbsf}$. The top of Subunit IB- 2 is placed where a transition to a thick interval of generally very low resistivity and high porosity occurs.

Interpretation: This is a partial cycle within a transgressive deepening; as such, it does not seem to have attained the "climax" stage of previous cycles. The upper portion of this subunit is probably a transition into a "maximum flooding" stage for this major deepening trend from Subunits IC-8 to IB-2. Therefore, the main transgressive phase of deepening has a relative duration of approximately two cycles. If these cycles are assumed to represent 100,000 yr Milankovitch, eccentricity-induced thermal expansion/contraction of the oceanic water column, then the main transgressive phase had a duration of at approximately $200,000 \mathrm{yr}$.

\section{Logging Facies Subunit IB-3 (102-115 mbsf; 13 m thickness)}

Core 144-879A-13R (111.8-121.5 mbsf; $0.04 \mathrm{~m}$ recovery): Piece of foraminifer wackestone.

Core 144-879A-12R (102.1-111.8 mbsf; no recovery).

102-115 mbsf: This interval has very low resistivity and sustained high porosity. Details of this interval are obscured by the widened borehole preventing sustained contact of the FMS logging tool, and internal structure is deduced from the recorded variations by the neutron porosity $\log$. When core $144-$ $879 \mathrm{~A}-12 \mathrm{R}$ was drilled, only 3 minutes were needed to penetrate $9.7 \mathrm{~m}$, which probably indicates an uncemented carbonate sand. (A cavern is not indicated by the drilling, because there was always resistance to the bit.) Three evenly spaced beds of relatively higher porosity are indicated at $112,108.5$, and $105 \mathrm{mbsf}$, which may be a deep-water equivalent of the 3.5 -m cyclicity noted in other subunits. The top of this subunit is placed at a rapid upward decrease in porosity.

Interpretation: Quiet lagoon facies of relatively uncemented foraminifer (and pellet?) packstone-grainstone. The single piece of wackestone recovered in this interval is probably not the dominant lithology. This interval may include three and a half cycles in the relative proportions of lime mud to skeletal grains.

\section{Logging Facies Subunit IB-4 (88-102 mbsf; 14 m thickness)}

Core 144-879A-IIR (92.5-102.1 mbsf; $0.2 \mathrm{~m}$ recovery): Rudist and "Bacinella" rudstone to boundstone with packstone matrix; extensively micritized with moldic porosity.

Core 144-879A-10R (82.9-92.5 mbsf; 0.3 m recovery): Skeletal grainstone-packstone of bivalve and coral fragments, gastropods, miliolid foraminifers, and cyanobacterial bushes (Ortonella), with a fragment of a coral colony and a lithoclast of fenestral wackestone. Grains are usually coated by micrite; and the cement includes isopachous fillings of fibrous calcite.

88-102 mbsf: The lower $4 \mathrm{~m}$ of this low-porosity interval displays a progressive upward increase in resistivity. Moderate peaks in resistivity are associated with very low porosity, indicating that well-cemented beds occur with an average of 3-m spacing. The FMS imagery indicates that some of these beds of higher resistivity have a sharp contact or rapid transition to the next overlying cycle (Fig. 8). Including the basal low-porosity bed, there are five major porosity-resistivity peaks; the top of this subunit is placed at the apparent sharp top of the uppermost peak. The upper half of this subunit has a higher average resistivity and lower porosity; furthermore, it contains several moderate concentrations of uranium, but not all of these concentrations coincide with the distinct peaks in resistivity.

Interpretation: This subunit is a series of upward-shallowing cycles developed in a shallow lagoonal environment. The base of this interval represents a relatively rapid shoaling; therefore, it is considered to be equivalent to a "sequence boundary." The associated core recovery indicates a shallow-water setting, and the fragment of fenestral wackestone may indicate intervals of peritidal conditions. 


\section{Logging Facies Subunit IB-5 (83-88 mbsf; 5 m thickness)}

83-88 mbsf: This interval has very low resistivity and relatively high porosity. This facies corresponds to the upper half of Core 144-879A-10R, which drilled at the rate of $1 \mathrm{~min} / \mathrm{m}$ compared with the typical rates of $5 \mathrm{~min} / \mathrm{m}$ for the lower half of the core within Subunit IB-4. The neutron porosity log suggests alternations of relative porosity at $1-\mathrm{m}$ intervals; and the relatively low-porosity beds correspond to minor concentrations of uranium.

Interpretation: This interval marks an episode of relative deepening that terminated the shallow-lagoon cycles of Subunit IB-4. The facies is probably poorly cemented foraminifer peloid packstone-grainstone, possibly with some oncolites.

\section{Logging Facies Subunit IB-6 (61-83 mbsf; 22 m thickness)}

\section{Core 144-879A-9R (73.2-82.9 mbsf; no recovery).}

Core 144-879A-8R (63.6-73.2 mbsf; no recovery).

61-83 mbsf: This interval has sustained low resistivity but relatively low porosity; drilling rates were rapid at $1 \mathrm{~min} / \mathrm{m}$. The neutron porosity record is irregular, but without any indications of the cyclicity observed in other subunits. Natural-gamma-ray intensity remains at background levels, except for a 2-m-thick interval at 70-72 mbsf of moderate uranium concentration, which appears to be associated with beds of relatively low porosity.

Interpretation: This interval is an uncemented facies of sustained low porosity, which is a combination unique to this subunit. One possibility consistent with the underlying and overlying lagoonal facies is a compacted lime mud or pelleted lime mud deposited in a quiet deep lagoon and fortuitously intact from later diagenetic cementation. Unfortunately, no core recovery is available to constrain the interpretation. This tentative assignment of a lime-mud-rich facies would place Subunit IB-6 in a transgressive and early highstand systems tract.

\section{Logging Facies Subunit IB-7 (52-61 mbsf; 9 m thickness)}

\section{Core 144-879A-7R (53.9-63.6 mbsf; no recovery).}

52-61 mbsf: Low resistivity with three alternations of high to medium porosity.

Interpretation: Poorly cemented lagoonal facies. The variable porosity suggests cycles of packstone and wackestone texture.

\section{Logging Facies Subunit IB-8 (39-52 mbsf; 13 m thickness)}

Core 144-879A-6R (44.3-53.9 mbsf; 0.15 m recovery): Foraminiferpeloid grainstone with cyanobacterial bushes (Ortonella), and intervals of mollusk to foraminifer wackestone; the coarse grainstone is extensively micritized.

39-52 mbsf: Low resistivity with high porosity. A relatively mediumresistivity peak at $47.5 \mathrm{mbsf}$ is associated with a slightly lower porosity.

Interpretation: The core recovery, plus the high porosity and low resistivity, indicates a dominance of poorly cemented foraminifer-peloid grainstone, with some intervals of wackestone texture. Episodes of intertidal conditions are suggested by asymmetric calcitic cements.

\section{Lithologic Subunit IA: Coral-mollusk Rudstone-floatstone with Skeletal Packstone Matrix (0.0-39.0 mbsf; $39.0 \mathrm{~m}$ thickness; late Aptian to Albian)}

\section{Summary of Logging Facies}

This interval has no direct logging record because of the presence of the drill pipe; however, the natural-gamma-ray and neutron porosity logs, which are only partially attenuated by the drill pipe, allow a general interpretation of the major trends in cementation and possible algal-cyanobacterial concentrations. These logs, when combined with the core recovery, enable tentative division of Subunit IA into three main intervals: Subunit IA-1 is a 4-m thick algal-cyanobacterial-rich zone; Subunit IA-2 has four major alternations of low- and moderate-porosity beds of progressively increasing thickness; and Subunit IA-3 is a 4-m thick interval of moderate porosity before truncation of the carbonate platform.

General Interpretation: Subunit IA represents the upper portion of the elevated south perimeter rim, which rises approximately $70-80 \mathrm{~m}$ above the interior platform surface. It was expected that this rim would yield a record of an active seaward "reef" or bioconstruction process. However, neither the limited logging data nor the core recovery indicates any evidence of a reeftype, open-marine bioherm in this interval. Subunit IA-1 is an oncolite-rich transition to a possible intertidal setting from the underlying restricted lagoonal facies of foraminifer-skeletal grainstone-packstone. Subunit IA-2 represents alternating accumulations of (a) coral- and bivalve-rich floatstone that have been wave redeposited (some beds may have been exposed to temporary intertidal settings, according to the asymmetric calcite cements) and (b) gastropod-rich peloid packstone indicating partially winnowed lagoonal-type deposits. Subunit IA-3 is a 4-m-thick deposit of winnowed, gastropod-rich "lagoonal-type" sediment, and is capped by a scoured silica- and phosphate-rich hardground. The nearest analogy for a similar suite of shallow-water carbonate facies associated with a topographic high is the coral-floatstone deposits that are washed lagoonward to form the island necklaces of modern Pacific atolls.

\section{Logging Facies Subunit IA-1 (35-39 mbsf; 4 m thickness)}

Core 144-879A-5R (34.6-44.3 mbsf; 0.8 m recovery): Oncolite-foraminifer grainstone is the dominant lithology, and includes fragments of green algae (dasyclads), echinoderms and gastropods. Minor lithologies include fenestral wackestone, bivalve rudstone, and skeletal oncolite packstone-floatstone. Cyanobacterial bushes (Ortonella) and "Bacinella" clumps are also present.

35-39 mbsf: A basal progressive increase in porosity (Subunit IA-1) is partially associated with a uranium concentration (37-39 mbsf).

Interpretation: Subunit IA-1 is a possible upward-shallowing transition from the underlying restricted lagoon through an oncolite-rich grainstone to a bioclastic floatstone facies. The low-porosity uppermost portion may be within intertidal depths, as suggested by the fenestral features on one piece of core recovery. This interval is considered to be equivalent to foraminifer "sands" on the lagoon side of modern atoll islands.

\section{Logging Facies Subunit IA-2 (4-35 mbsf; 31 m thickness)}

Core 144-879A-4R (25.0-34.6 mbsf; $0.1 \mathrm{~m}$ recovery): Oyster floatstone, peloid grainstone with echinoids and cyanobacterial bushes (Ortonella), and skeletal packstone with thin-shelled bivalves and few gastropods.

Core 144-879A-3R (15.5-25.0 mbsf: 0.8 m recovery): Bivalve rudstone with packstone matrix, algal-mollusk floatstone with encrusting red algae, and grainstone of coated grains.

Core 144-879A-2R (6.0-15.5 mbsf; $1.5 \mathrm{~m}$ recovery): Oyster floatstone with packstone matrix is dominant facies. Minor lithologies include a coral floatstone with wackestone matrix.

4-35 mbsf: The porosity log, after omitting low-porosity artifacts caused by the 10-m-spaced drill-pipe connections, indicates approximately four successions of high porosity grading upwards to a low-porosity bed. The thicknesses of these successions, measuring between the relative sharp tops of the lowporosity beds, appear to increase progressively from 6, to 7 , to 8 , and then to $10 \mathrm{~m}$.

Interpretation: The limited core recovery is the main basis for interpretation of the facies of Subunit IA-2. The dominant sedimentation appears to be wave-redeposited coral-rich floatstone deposited into a winnowed lagoonaltype environment. The successions are alternations of (a) an open-marine, highenergy environment of floatstone comprised of winnowed bioclasts of corals, bivalves (including rounded fragments of oysters and rudists), benthic foraminifers, and cyanobacterial components (Ortonella and oncolites); and (b) a more lagoonal facies of gastropod and bivalve-rich peloid packstone. Winnowing and redeposition by storms probably deposited bars of coarse debris into the lagoonal-type setting. Episodes of intertidal bioclastic shoals are suggested by asymmetric calcite cements in grainstone in the middle of Core 144-879A-2R.

\section{Logging Facies Subunit IA-3 (0-4 mbsf; 4 m thickness)}

Core 144-879A-IR (0.0-6.0 mbsf: $0.2 \mathrm{~m}$ recovery): Gastropod-bivalve floatstone to coquina, with matrix of peloidal packstone. Bioclasts include orbitolinid foraminifers, echinoids, green algae, gastropods, and encrusting red algae as rhodoliths or as reworked bushes (Solenoporaceans).

0-4 mbsf: The uppermost 4-m interval may represent a fifth cycle continuing the alternations of Subunit IA-2, but it is sharply truncated by the upper surface of the guyot.

Interpretation: This assemblage was from bioclastic sand shoals in a high-energy setting. The uppermost layers do not appear to have undergone any unusual cementation or secondary porosity which may indicate emergence; however, a downhole-displaced piece at the top of Core 144-879A-5R indicates the presence of a silica- and phosphate-rich encrustation that is at least $0.5 \mathrm{~cm}$ thick. 